\title{
Reversing GABA polarity corrects synaptic physiology and behavioural deficits in young adolescent Syngap1+/- mice
}

\section{Vijaya Verma}

Jawaharlal Nehru Centre for Advanced Scientific Research

\section{MJ Vijay Kumar}

Jawaharlal Nehru Centre for Advanced Scientific Research

\section{Kavita Sharma}

Jawaharlal Nehru Centre for Advanced Scientific Research

\section{Sridhar Rajaram}

Jawaharlal Nehru Centre for Advanced Scientific Research

Ravi Muddashetty

InStem

\section{Ravi Manjithaya}

Jawaharlal Nehru Centre for Advanced Scientific Research

Thomas Behnisch

2Institutes of Brain Sciences, Fudan University

James Clement ( $\nabla$ clement@jncasr.ac.in )

Jawaharlal Nehru Centre for Advanced Scientific Research

\section{Research Article}

Keywords: Autism spectrum disorder, Intellectual disability, Syngap1 heterozygous mutation, GABA, NKCC1, KCC2, GSK-3 $\beta$

Posted Date: July 6th, 2021

DOI: https://doi.org/10.21203/rs.3.rs-682039/v1

License: (c) (i) This work is licensed under a Creative Commons Attribution 4.0 International License. Read Full License 
3 Vijaya Verma ${ }^{1 \#}$, MJ Vijay Kumar ${ }^{1}$, Kavita Sharma ${ }^{5}$, Sridhar Rajaram ${ }^{5}$, Ravi Muddashetty ${ }^{3}$, Ravi Manjithaya ${ }^{1 \& 4}$,

4 Thomas Behnisch ${ }^{2}$, James P. Clement ${ }^{1 *}$

$5 \quad{ }^{1}$ Neuroscience Unit, Jawaharlal Nehru Centre for Advanced Scientific Research, Bangalore, 560064, India; ${ }^{2}$ Institutes

6 of Brain Sciences, Fudan University, Shanghai, 200032, China; ${ }^{3}$ Institute for Stem Cell Biology and Regenerative

7 Medicine, Bangalore, 560065, India; ${ }^{4}$ Molecular Biology and Genetics Unit, Jawaharlal Nehru Centre for Advanced

8 Scientific Research, Bangalore, 560064, India; ${ }^{5}$ International Centre for Material Sciences, Jawaharlal Nehru Centre

9 for Advanced Scientific Research, Bangalore, 560064, India.

10 *corresponding author. Email: clement@jncasr.ac.in Phone:+91-08-22082613 \#joint corresponding author

\section{Abstract:}

12 Haploinsufficiency in SYNGAP1 is implicated in Intellectual Disability (ID) and Autism Spectrum disorder (ASD)

13 and affects the maturation of dendritic spines. The abnormal spine development has been suggested to cause disbalance

14 of excitatory and inhibitory (E/I) neurotransmission at distinct developmental periods. In addition, E/I imbalances in

15 Syngap $1^{+/}$mice might be due to abnormalities in $\mathrm{K}^{+}-\mathrm{Cl}^{-}$co-transporter function (NKCC1, $\mathrm{KCC} 2$ ), in a similar manner

16 as in the murine models of Fragile-X and Rett syndromes. To study whether an altered intracellular chloride ion

17 concentration represents an underlying mechanism of altered function of GABAergic synapses in Dentate Gyrus

18 Granule Cells of Syngap 1 ${ }^{+/}$recordings were performed at different developmental stages of the mice. We observed 19 that neurons at P14-15 of Syngap 1 ${ }^{+/}$mice had depolarised membrane potential and a decreased $\mathrm{Cl}^{-}$reversal potential.

20 The KCC2 expression was decreased compared to Wild-type (WT) mice at P14-15. Furtherly, the small molecule

21 GSK-3 $\beta$ inhibitor, 6-bromoindirubin-3 -oxime (6BIO), was tested in an attempt to restore the function of GABAergic

22 synapses. We discovered that intraperitoneal administration of $6 \mathrm{BIO}$ during the critical period or young adolescents

23 normalized an altered E/I balance, the deficits of synaptic transmission, and behavioral performance like social

24 novelty, anxiety, and memory of the Syngap $1^{+/}$mice. In summary, altered functionality of GABAergic synapses in

25 Syngap $1^{+/}$mice is based on a reduced $\mathrm{KCC} 2$ expression and a subsequent increase in the intracellular chloride 
concentration that can be counteracted by the small molecule $6 \mathrm{BIO}$. The $6 \mathrm{BIO}$ sufficiently restored cognitive,

27 emotional, and social symptoms by pharmacological intervention, particularly, in adulthood.

Keywords:

29 Autism spectrum disorder, Intellectual disability, Syngap1 heterozygous mutation, GABA, NKCC1, KCC2, GSK-3ß

Declarations:

\section{1}

32

\section{Funding resources:}

The work was supported in part by grants to JPC from DST-SERB (SB/YS/LS-215/2013, and EMR/2016/004795), DBT-JNCASR collaborative fund, to RSM in part, by Dept. of Biotechnology, India (BT/PR8723/AGR/36/776/2013, and BT/IN/Denmark/07/RSM/2015-2016), to TB by NSFC (31871076) and intramural funding from all the institutes.

\section{Conflict of interest:}

The authors report no conflict of interest.

Availability of data and material: All raw data obtained for each experiment is available on request

Code availability: Not applicable

\section{Author Contributions:}

Electrophysiological recordings, mRNA studies, immunoblotting, immunohistochemistry and behavioural studies were performed by VV; behaviour analysis was done by MJVK; VV, and JPC designed the experiments; TB, and RSM provided technical assistance in $\mathrm{E}_{\mathrm{Cl}^{-}}$and tonic current experiments, mRNA, immunoblotting studies respectively; K.S. and S.R. synthesised and provided 6BIO; JPC conceived the study; VV and JPC wrote, and VV, RSM, RM, TB, and JPC edited the manuscript.

Ethics approval: All the experiments were performed in accordance with the Institutional Animal Ethics Committee (IAEC; Chair: Prof Anuranjan Anand) and Committee for the Purpose of Control and Supervision of Experiments on Animals (CPCSEA).

Consent to participate: Not applicable 
Content for publication: All authors have given consent to publish this manuscript in the current format.

50

51

\section{Acknowledgements:}

We would like to thank Prof. Ted Abel and Dr Joseph C. Glykys for the critical comments about the concept and the data. We would like to thank Drs. Elizabeth Nicholson, Milos Petrovic, Emin Ozkan, and Jonathan Brown for valuable suggestions on perforated patch experiments. We thank Ginni Khurana and Shruthi Sateesh for their technical inputs in immunoblotting and IHC. We thank Zahid MD for assisting in behavioural experiments. We thank Prof. Vidita Vaidya, Sonali Salvi, Sukrita Deb and other lab members for their technical contributions in mRNA experiments. We thank Suma BS for the technical inputs in confocal imaging. We thank Drisya Dileep, Ankita Kapoor, Lakshmi Balasubramaniam and Shubham Kesarwani for their technical inputs in the analysis of IHC images. We thank RM, Preeti Kute, Bharti Nawalpuri and other lab members for the technical inputs in immunoblotting experiments. We thank Clement lab and Dr Sthitapranjya Pati for all technical and conceptual suggestions towards this manuscript. We thank Dr Aditi Bhattacharya and Prof Upinder Bhalla for their critical comments on this manuscript.

(1)

\section{Introduction:}

Precise regulation of synaptic composition and function during the early stages of neuronal development (Bliss and Collingridge 1993) through the molecular mechanisms of synaptic plasticity is fundamental for appropriate cognitive abilities in adulthood. Mutations in gene encoding proteins that regulate synaptic function disrupt this phenomenon and have been linked to the onset of neurodevelopmental brain-related disorders such as autism spectrum disorders (ASD) and Intellectual Disability (ID) (Bear, Huber, and Warren 2004; Penzes et al. 2011). One of the genes that have been implicated in ASD/ID is SYNGAP1. SYNGAP1 encodes for RAS-GTPase-activating protein SYNAGP1 (Hamdan et al. 2011; Berryer et al. 2013; Kilinc et al. 2018; Kimura et al. 2018; Vlaskamp et al. 2019). Neuropathophysiological hallmarks of the heterozygous Syngap1 mouse strain $\left(\right.$ Syngap1 $\left.{ }^{+-}\right)$are enhanced excitatory neurotransmission, premature development of synapses, and an Excitation/Inhibition (E/I) imbalance. All these alterations during the development cause distortion of synaptic function and manifest abnormal cognitive and social behaviours in adulthood (Clement et al. 2012; Ozkan et al. 2014; Jeyabalan and Clement 2016; Clement et al. 2013; Muhia et al. 2010; Komiyama et al. 2002; Guo et al. 2009). 
75 Syngap $1^{+/}$mice display improper glutamatergic synapse development and function; however, the trophic role of 76 GABA in shaping synaptic function during development is unknown (Clement et al. 2012; Ozkan et al. 2014; Clement 77 et al. 2013; Jeyabalan and Clement 2016; Kepecs and Fishell 2014; Ben-Ari 2002). Studies have shown that GABA 78 exhibits trophic function - excitatory and inhibitory in early and late stages of development, respectively - regulated by potassium-chloride $\left(\mathrm{Cl}^{-}\right)$co-transporters like $\mathrm{KCC} 2$ and $\mathrm{NKCC} 1$. The $\mathrm{NKCC} 1$ expression level is age-dependently regulated and highest in the early stages of the development that allows influx of $\mathrm{Cl}^{-}$. In contrast, the $\mathrm{KCC} 2$ expression

81 is high in the later stages of development, thereby, extrudes intracellular $\mathrm{Cl}^{-}$from the neuron. Hence, the intracellular

$82 \mathrm{Cl}^{-}$concentration determines GABA-mediated responses that can further regulate the synaptogenesis during development (Ben-Ari 2002; Ben-Ari et al. 2012; Gamba 2005; Rivera, Voipio, and Kaila 2005; Blaesse et al. 2009; Rivera et al. 1999). Alteration in the intracellular basal chloride concentration modulates the electrochemical gradient $\left(\mathrm{E}_{\mathrm{GABA}}\right)$ of the chloride ion flow through the chloride conductive $\mathrm{GABA}_{\mathrm{A}}$ receptor/channels and thus affecting the strength of inhibitory action in a neuronal network. Thus, a switch between excitatory or inhibitory action of $\mathrm{GABA}_{\mathrm{A}}$ receptor/channels is mediated by the expression level of potassium-chloride-co-transporters. The disruption of the cotransporter expression during the critical period impairs synapse formation and function as it has been reported in several ID/ASD-like animal models (He et al. 2014; Hyde et al. 2011; Duarte et al. 2013; Deidda, Allegra, et al. 2015). Besides, reversing the polarity of $\mathrm{GABA}_{\mathrm{A}}$ mediated chloride flow before the end of the critical period of mouse

91 development by bumetanide corrected $\mathrm{E}_{\mathrm{GABA}}$, synaptic function, and phenotypes in Down's, Fragile -X and Rett syndrome-like animal models (He et al. 2019; Deidda, Parrini, et al. 2015; Banerjee et al. 2016). Thus, normalization 93 of the reversal potential for chloride (here called GABA polarity) could represent a putative target for therapeutic 94 intervention in ID/ASD.

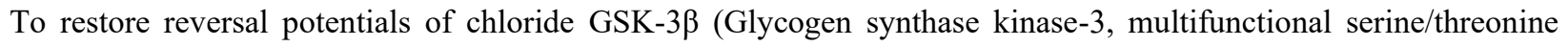
kinase) has been suggested, which is pivotal in synaptic plasticity (Yao et al. 2002; Salcedo-Tello, Ortiz-Matamoros,

97 and Arias 2011). Increased activity of GSK-3 $\beta$ is a major contributor to the ID/ASD pathophysiology and inhibiting 98 GSK-3 $\beta$ reversed many of their phenotypes (Min et al. 2009; Mines and Jope 2011). Nevertheless, finding potent therapeutics that can target GSK-3 $\beta$ and restore phenotypes, when administered after a critical period of development,

100 has been elusive. Therefore, the opportunity exists to develop a therapeutically viable GSK-3 $\beta$ inhibitor that can 101 restore the phenotypes. We report a GSK-3 $\beta$ inhibitor, 6-bromoindirubin-3'-oxime (6BIO) that has been described to 
cross the blood-brain barrier and to be neuroprotective in an MPTP-based model of Parkinson's disease (Meijer et al. 2003; Vougogiannopoulou and Skaltsounis 2012; Polychronopoulos et al. 2004; Suresh et al. 2017).

104

105

Given the minimal knowledge of GABAergic function during development in Syngap1 ${ }^{+/}$, we hypothesised that the GABA-mediated function regulated by chloride co-transporter expression and function is disrupted during development in Syngap1 ${ }^{+-}$. Thus, reversing the GABA function may restore phenotypes to a Wild-type level, particularly after the critical period of development.

\section{Materials and Methods:}

\section{Experimental Animals:}

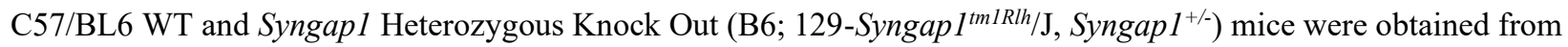
The Jackson Laboratory, USA, and inbred and maintained in the Institute's animal house under 12 hours dark and light cycle. Food and water were supplied ad libitum. All the experiments were performed in accordance with the Institutional Animal Ethics Committee (IAEC; Chair: Prof Anuranjan Anand) and Committee for the Purpose of Control and Supervision of Experiments on Animals (CPCSEA). Female and male mice were studied in all experiments except in behaviour experiments where only male mice were observed. The experimenter was blind to the genotypes until the completion of the experiment.

\section{Protein lysate preparation:}

Hippocampal lysates were prepared from Wild Type (WT) and Syngap1 ${ }^{+/}$littermates of (P: Postnatal day) P4, P7, P8, $\mathrm{P} 14-15, \mathrm{P} 21-23$, and $\mathrm{P} \geq 90$ in Phosphate Buffer Saline (PBS; $\mathrm{pH}$ 7.4). Homogenisation was done in $7 \mathrm{ml}$ Dounce tissue homogenizer (Sigma, \#D9063), containing RIPA Buffer (mM): $150 \mathrm{NaCl}$ (Sigma, \#S6191), 50 Tris-Cl, (Thermo Fischer Scientific, \#15965), HCl (Merck Millipore, \#HC301585), pH 7.4, $0.25 \%$ Sodium deoxycholate (Sigma Aldrich, \#D6750), 5 EDTA (Merck Millipore, \#324502), $0.10 \%$ SDS (BioRad, \#1610302), $0.10 \%$ Triton X (HiMedia, \#RM845), $10 \mu \mathrm{l} / 100 \mathrm{ml}$ protease-inhibitor cocktail (Roche, \#11836170001), $2 \mu \mathrm{l} / 100 \mathrm{ml}$ phosphatase inhibitor cocktails (Sigma Aldrich, \#P2850 - cocktail 1, P5726 - cocktail 2, \#P0044 - cocktail 3) in ice. After homogenisation, tissue was kept in ice for 30-minute and further processed by centrifugation (Eppendorf, \#5920R) at 

PE) until further use.

SDS-PAGE (Sodium dodecyl sulphate-Polyacrylamide gel electrophoresis (BioRad, \# 1703812) and western blotting were performed by mixing samples with $5 \mathrm{X}$ dye (Tris-Cl pH 6.8, bromophenol blue dye (Thermo Fisher Scientific, \#R0611), glycerol (Fischer scientific, \#0854), DTT (di thioetriol) (HiMedia, \#RM525) or 2-Mercaptoethanol (Himedia, \#MB041). For NKCC1, samples were resolved in $5 \%$ stacking gel and $8 \%$ resolving gel and electrophoresed for approximately 3-hour followed by wet transfer for 3-hour at $80 \mathrm{~V}$. Blocking was done in $5 \%$ skimmed milk (Himedia, \#M530) for 1-hour followed by incubation in anti-NKCC1 (Sigma Aldrich, \#AV43805), and anti- $\beta$-ACTIN (Thermo Fisher Scientific, \#GX2781) primary antibodies for 12-hour followed by 3 washes with PBST (PBS and $1 \%$ Tween20 (Himedia, \# GRM156) and $0.1 \%$ Tween20 (Himedia, \# GRM156). Then, 1-hour incubation in secondary antibody, Goat Anti-rabbit (BioRad, \#1721019) in skimmed milk. After three washes with PBST, signals were visualised by the chemiluminescent method. For KCC2, the same procedure was followed except that samples were prepared in dye without DTT but in $3 \%$ 2-Mercaptoethanol, and resolved in 3-8 \% Tris-acetate gel (Thermo Fisher Scientific, \#EA03752), and transferred overnight (16-hour) (Blaesse et al. 2006). Blots were probed with anti- $\alpha$-TUBULIN (CST, \#2144S) and anti-KCC2 (Sigma Aldrich, \#C2366) antibodies and visualised as mentioned earlier. The combined intensity of both the bands observed in the case of KCC2 after chemiluminescent assay were considered for the analysis and plotted as a scatter plot with smooth lines and markers (mean $\pm \mathrm{SEM}$ ).

\section{Quantitative Reverse Transcriptase Polymerase Chain Reaction (qPCR) analysis:}

mRNA expression levels of $N k c c 1, N k c c 2, K c c 1, K c c 2, K c c 3$, and $K c c 4$ were measured in male and female WT and

147 Syngap $1^{+/-}$from P14-15 mice. All primers procured from Eurofins and summarised in Table 1. Briefly, hippocampus 148 samples were frozen immediately after dissection, in liquid nitrogen $\left(\mathrm{N}_{2}\right)$ and kept in different vials and stored at $14980^{\circ} \mathrm{C}$ till homogenisation. RNA was prepared in $500 \mathrm{ml}$ of Trizol (Sigma Aldrich, \#T9424) at room temperature (RT) in $1 \mathrm{ml}$ Dounce homogeniser (Wheaton, \#357538), and $200 \mu \mathrm{l}$ of $\mathrm{CHCl}_{3}$ (Fisher Scientific, \# BP1145-1) was added 151 and kept at RT for 5-minute. The whole mix was centrifuged at $4^{\circ} \mathrm{C}$ at $12,000 \mathrm{rpm}$ for 20 -minute. The upper aqueous 152 phase was transferred to a fresh tube, and $95 \%$ isopropanol (Sigma Aldrich, \#59304) was added to it and incubated 153 at RT for 1 -hour followed by centrifugation at $4^{\circ} \mathrm{C}$ at $10,000 \mathrm{rpm}$ for 20 -minute. Pellet was washed with $70 \%$ ethanol 
(Merck Millipore, \#100983) and centrifuged at $4^{\circ} \mathrm{C}$ at 10,000 rpm for 10-minute. The washing step was repeated twice, and the pellet was air-dried. Pellet was resuspended in $20 \mu 1$ of nuclease-free water (Thermo Fisher Scientific, \#AM9932), and RNA concentration was assessed in nanodrop. PCR was performed for cDNA synthesis by using a cDNA synthesis kit (Takara, \#TP600) and aliquoted and stored at $-80^{\circ} \mathrm{C}$ till further use. qPCR reaction was set up in duplicates using SYBR Mix (Roche, \#light cycler 480), and probes for the genes mentioned above. Cq values were calculated by the $\mathrm{ddC}_{t}$ method, in which $\mathrm{dC}_{t}$ was calculated by subtracting test gene value from housekeeping gene value and then taking $2^{\wedge}-\mathrm{dC}_{\mathrm{t}}$ as $\mathrm{Cq}$ value. The relative mRNA level, 2-ddCt, was plotted.

\section{Cryosectioning and Immunofluorescence (IF):}

For immunohistochemical analysis, $\mathrm{P} 8, \mathrm{P} 14-15$, and $\mathrm{P} \geq 90$ male and female mice were anaesthetised with halothane (Alem, \#M14A) and perfused with ice-chilled $150 \mathrm{ml}$ PBS followed by $150 \mathrm{ml}$ of $4 \%$ paraformaldehyde (PFA) (Sigma Aldrich, \#158127) $\sim 50$ ml/minute using a peristaltic pump (Ravel Hiteks \#RH-P110S-25). The brain was dissected out and incubated in $4 \%$ PFA overnight, followed by incubation in $30 \%$ sucrose (Sigma Aldrich, \#S9378) till it submerged to the bottom and stored at $-80^{\circ} \mathrm{C}$ until further use. The brain was kept in Optimum Cutting Temperature (OCT) solution (Trivitron, \#DIG-46181) and incubated for 20 -minute inside cryotome at $-20^{\circ} \mathrm{C}$ (Leica, \#CM3050). $30 \mu \mathrm{m}$ sections were obtained and stored in $1 \mathrm{X}$ PBS. Antigen retrieval was performed by treating sections with Sodium citrate buffer (Fisher Scientific, \#27625), pH 6.0 for 30-minute followed by three washes, 10-minute each, by $0.1 \%$ PBSTx [0.1\% Triton X 100 (Himedia \#RM845) in PBS] and then blocking [2 \% BSA (Himedia, \#GRM105) + 1 \% Goat Serum (MP Bio, \#0219135680) + 0.1 \% PBSTx incubation for 4-hour at RT]. Sections were given three washes with $0.1 \%$ PBSTx for 10-minute each and then incubated in anti-KCC2, and anti-SYNGAP1 antibody for 2-hour at RT and 34-hour at $4^{\circ} \mathrm{C}$ followed by three washes with $0.1 \%$ PBSTx and kept in secondary antibody (Thermo Fisher Scientific, Alexa Flour 633 goat anti-mouse, \#A21052 and Alexa Flour 555 goat anti-rabbit, \#A21428) for 4-hour at RT. Secondary incubation was followed by three washes with $0.1 \%$ PBSTx and then incubation in Hoechst (Thermo Fisher Scientific, \#H3570) for 10-minute followed by a wash of 10-minute with PBS. Sections were mounted in Vectashield (Vector, $\# \mathrm{H}-1000)$ on slides. All the imaging was performed in a confocal laser scanning microscope (LSM 880, Zeiss, India) and analysed using ImageJ software. Dentate gyrus granular cells (DGGC) were chosen for imaging and all the images were acquired with a confocal-fluorescence microscope equipped with a $63 \mathrm{X}$ objective. A Z-stacks of 30 images were acquired and images \#10 to \#24 were considered for analysis. 
The maximum intensity projection (MIP) image over 15 confocal images of a Z-stack was calculated and analysed. Image thresholds were kept constant to quantify the expression of $\mathrm{KCC} 2$ for all genotypes and age groups. The integrated density of the isolated areas was calculated to measure the mean intensity (Madhwal et al. 2020; Shim, Mukherjee, and Banerjee 2012). In representative images (MIP images), punctate structures indicate expression of KCC2 (red colour), and SYNGAP1 (green colour) on the YFP background (yellow colour). Thy1-Yfp-Syngap1 ${ }^{+/-}$mice were studied to identify the labelling of excitatory neurons. The whole area of the image represented along with YFP expressing neurons was considered for the analysis. The analysis of genotypes was performed in parallel, and the statistical comparison between groups was evaluated with the Unpaired Student's $t$-test.

\section{Preparation of Hippocampal Slices:}

Acute brain slices were prepared from WT and Syngap1 ${ }^{+/}$mice from P4-5, P7, P8, P14-15, P21-23, and P $\geq 90$ sacrificed by cervical dislocation. Following decapitation, the brain was removed and kept in an ice-cold (almost frozen) cutting solution containing (mM): 189 Sucrose (Sigma Aldrich, \#S9378), 10 D-Glucose (Sigma Aldrich, \#G8270), $26 \mathrm{NaHCO}_{3}$ (Sigma Aldrich, \#S5761), $3 \mathrm{KCl}$ (Sigma Aldrich, \#P5405), 10 MgSO $4.7 \mathrm{H}_{2} \mathrm{O}$ (Sigma Aldrich, \#M2773), $1.25 \mathrm{NaH}_{2} \mathrm{PO}_{4}$ (Sigma Aldrich, \#S8282), and 0.1 CaCl 2 (Sigma Aldrich, \#21115). After 30-second, the brain was glued to the brain holder of a vibratome (Leica, \#VT1200S), $350 \mu \mathrm{m}$ thick slices were prepared, and the cortex was dissected to isolate the hippocampus. All the slices were kept at $37^{\circ} \mathrm{C}$ in a water bath (Thermo Fisher Scientific, \#2842) for 50-minute in a slice chamber containing aCSF (artificial cerebrospinal fluid) composed of (mM): $124 \mathrm{NaCl}$ (Sigma Aldrich, \#S6191), $3 \mathrm{KCl}, 1 \mathrm{MgSO}_{4} .7 \mathrm{H}_{2} \mathrm{O}, 1.25 \mathrm{NaH}_{2} \mathrm{PO}_{4}, 10$ D-Glucose, $24 \mathrm{NaHCO}_{3}$ and $2 \mathrm{CaCl}_{2}$ bubbled with carbogen $\left(5 \% \mathrm{CO}_{2}\right.$ and $95 \% \mathrm{O}_{2}$; Chemix, India). Following recovery, slices were maintained at $\mathrm{RT}$ until transferred to a submerged chamber of $\sim 1.5 \mathrm{ml}$ volume in which the slices were perfused continuously $(2-3 \mathrm{ml} / \mathrm{minute})$ with warmed $\left(34^{\circ} \mathrm{C}\right)$ and carbogenated aCSF.

\section{Perforated and Whole-Cell Patch-Clamp Recordings:}

The reversal potential of $\mathrm{GABA}_{\mathrm{A}} \mathrm{R}\left(\mathrm{E}_{\mathrm{GABA}}\right)$ was measured using Gramicidin (Sigma Aldrich, \#G5002) based perforated patch-clamp of DGGC (Dentate Gyrus Granule Cells) from WT and Syngap 1 ${ }^{+/}$littermates at P4-5, P7, P8, P14-15, P21-23, and P $\geq 90$. 5-6 M $\Omega$ glass electrode (ID: 0.69mm, OD: 1.2mm, Harvard Apparatus) tip was filled with an internal solution containing (mM): $130 \mathrm{~K}$-Gluconate (Sigma Aldrich, \#P1847), $20 \mathrm{KCl}$ (Sigma Aldrich, \#P5405), 10 HEPES free acid (OmniPur Merck Millipore, \#5310), 0.2 EGTA (OmniPur Merck Millipore, \#4100), ATP and 
GTP, then backfilled with $100 \mu \mathrm{M}$ Gramicidin. GABAR-mediated currents were evoked using a bipolar stimulating electrode (CBARC75, FHC, USA) connected to a constant current stimulator (Digitimer, UK) and by holding the cell at different membrane potentials ranging from -100 to $+40 \mathrm{mV}$ in the presence of AMPAR and NMDAR blockers, 10 $\mu \mathrm{M}$ 6-Cyano-7-nitroquinoxaline-2,3-dione disodium (CNQX) (Tocris, \#1045) and $100 \mu \mathrm{M}$ (2R)-amino-5phosphonovaleric acid (DL-AP5) (Tocris, \#3693) respectively. Whole-cell recordings were performed to measure giant depolarising potentials (GDPs) and tonic currents mediated by GABARs by holding the neurons in DGGC at $70 \mathrm{mV}$. In the case of GDP, K-Gluconate based internal solution (composition is the same as described earlier) was used, and $10 \mu \mathrm{M}$ Bicuculline (Bic) was bath applied after recording 10-minute of baseline. Tonic currents were measured using $\mathrm{CsCl}$ based internal solution containing (mM): $120 \mathrm{CsCl}$ (Sigma Aldrich, \#289329), 10 HEPES free acid, 10 EGTA, $4 \mathrm{MgCl}_{2}$ (Sigma Aldrich, \#M8266), 5 Lidocaine N-ethyl bromide (Sigma Aldrich, \#5783), ATP and GTP. To isolate GABA-mediated currents, we bath applied AP-5 $(50 \mu \mathrm{M})$ and CNQX $(10 \mu \mathrm{M})$ for 10-minute followed by NO-711 hydrochloride (1-2-(Diphenylmethylene)iminooxyethyl-1,2,5,6-tetrahydro-3-pyridinecarboxylic acid hydrochloride; GAT-1 inhibitor to increase the ambient GABA concentration; $20 \mu \mathrm{M}$ was used; Sigma Aldrich, \#N142) for 10-minute, and then tonic currents were blocked by Bicuculine (20 $\mu \mathrm{M})$ (Cope et al. 2009). An increase

222 in holding current after the application of Bicuculine was calculated and plotted against current amplitude in the 223 presence or absence of Bicuculine. Cells showing a holding current of $<-30 \mathrm{pA}$ were discarded from the analysis 224 except for the cells in which $\mathrm{CsCl}$ was used as an internal solution. The data are based on experiments with at least three mice $(\mathrm{N})$ or more, and slices of 5 or more (n) per group.

\section{Extracellular Field Recordings:}

227 Field excitatory postsynaptic potential (fEPSP) were elicited by placing a concentric bipolar stimulating electrode 228 connected to a constant current isolator stimulator unit at Schaffer-collateral commissural pathway and recorded with

229 a 3-5 M 2 resistance glass pipette filled with aCSF. Signals were amplified using an Axon Multiclamp 700B amplifier 230 (Molecular Devices), digitised using an Axon Digidata 1440A (Molecular Devices), and stored on a computer using 231 pClamp10.7 software (Molecular Devices). Stimulation frequency was set at $0.05 \mathrm{~Hz}$. A baseline period of 15-minute 232 fEPSP was recorded at a stimulation intensity that elicited an approximately half-maximal response. Following the 233 baseline period, the theta-burst stimulation (TBS) was delivered consisting of five bursts at $5 \mathrm{~Hz}$ (theta frequency), 234 repeated four times at an interval of $20 \mathrm{~s}$ (Booth, Brown, and Randall 2014). fEPSPs after TBS were recorded for 45 
minutes. Slices with a high fibre volley (FV)/fEPSP ratio and unstable baseline were discarded from the analysis. Data analysis was performed using Clampfit 10.7 and Excel 2019. 2-Way ANOVA was performed to determine the

237 statistical significant difference between the last 3-minute of baseline and post-LTP. Example traces are those recorded 238 for 5-minute around the time point indicated in the graph.

\section{Behavioural Studies:}

In the small molecule study, the mice in the drug group were administered intraperitoneally with $5 \mathrm{mg} / \mathrm{kg}$ of $6 \mathrm{BIO}$. All four experimental groups of mice of three different age groups (Figure 3A) were kept in the behaviour room for at least 20-minute before behaviour experiments. The light intensity was maintained at 90-110 LUX. The experimenter who analysed the data was blind to the experimental groups.

\section{Open-Field test (OFT)}

245

OFT was conducted in a $52 \times 50 \times 45 \mathrm{~cm}$ custom-made white plywood wooden box in JNCASR. Mice were left at the periphery in one of the corners of the box and allowed to explore the arena for 15 minutes. Before introducing other

247 mice, the arena was cleaned with $70 \%$ ethanol and left for 5-minute air dry. The activity of the mice was recorded with SMART v3.0.04 (Panlab Harvard Apparatus \#DCBA5-E83) and a video camera (SONY \#SSC-G118). Total distance travelled, and the number of entries to the centre was determined by SMART v3.0.04 (Panlab Harvard Apparatus \#DCBA5-E83).

\section{Novel object recognition (NOR)}

252 The NOR was performed in a custom-made wooden box $35 \times 35 \times 35 \mathrm{~cm}$ in JNCASR. On Day-1, mice were familiarised 253 with the arena without the objects for 5-minute. Day-2 and Day-3 sessions included habituation with two familiar 254 objects placed diagonally to each other, and mice were allowed to explore the objects for 10 minutes. The day-4 255 session involved the recognition memory test 24 hours after the last training. The time the mice explored the novel 256 object and a familiar object placed diagonally was taken within 10 minutes (Lueptow 2017; Leger et al. 2013). The 257 time of interaction of the mice (sniffing/touch) to familiar and novel objects was acquired manually using stopwatches. 258 The discrimination index (DI) for novel object recognition test (NOR) [(time spent with novel object - time spent with 259 familiar object)/(time spent with novel object + time spent with familiar object)] X 100, was calculated and taken as a measure of the strength of object recognition (either novel or familiar). DI values above 25 correlated with memory 
261 and below 25 correlated with a lack of memory. In addition, the mice behaviour was monitored and protocolled by a Handycam (SONY \#HDR-CX405).

264 SI and SP were performed in a custom made transparent three-chamber plexiglass box $40.6 \times 21 \times 35 \mathrm{~cm}$ in JNCASR.

265 In the first session of the experiment, the mouse was habituated to the three-chambered glass box for 5-minute. In the 266 second session, the chambers were closed with doors, and the mouse was placed in the middle chamber and allowed

267 to explore for 5-minute. In the third session, two steel mesh jars were kept in either of the adjacent chambers - one

268 had a mouse of the same gender and age and the other was empty. The test mouse was introduced into the middle 269 chamber, the doors were removed, and the mouse explored the whole arena for 10-minute (Nakajima et al. 2019).

270 Social interaction was calculated by the time spent between the empty jar and familiar mice. In the last session, the

271 mouse of the same gender and age was introduced into the empty mesh jar, and the test mouse was allowed to explore

272 and interact with both the mice placed beneath the mesh jars. Social preference was calculated by the time spent

273 between familiar and unfamiliar mice. The time mouse spent climbing over the mesh jar was not taken into 274 consideration in the analysis. SI and SP were recorded using Handycam (SONY \#HDR-CX405).

\section{Flurothyl-induced seizure}

276 Seizures were induced using $10 \%$ flurothyl (Sigma Aldrich \#287571) and $95 \%$ ethanol (Merck \#K46475383 511) as 277 solvent at the rate of $20 \mu \mathrm{l} /$ minute using a Syringe pump (New era pump system \#NE-1000). The analysis was done 278 manually by counting the time of tonic-clonic seizure (Kadiyala et al. 2014; Samoriski and Applegate 1997).

\section{Statistics:}

280 All graphs were plotted, and statistical analysis was performed in Microsoft Excel (2019) and Prism GraphPad (version 281 8.3). Data are presented as Mean \pm Standard Error of Mean (SEM) except for box and whisker plots. Unpaired Student's $282 t$-test assessed the genotype difference for a given age group while Two-way ANOVA followed by Tukey's post-hoc 283 to determine genotype difference across other age groups unless otherwise mentioned.

284 Results: 
We asked whether E/I imbalance during development a consequence of GABA-mediated dysfunction at the neuronal circuit level is by measuring giant depolarisation potentials (GDPs) and GABA-mediated activity from dentate gyrus granular cells (DGGC) (Ben-Ari et al. 1989; Griguoli and Cherubini 2017; Sipila et al. 2005). In the absence of 10 $\mu \mathrm{m}$ bicuculline, no significant differences in GDP were observed between genotypes. However, in the presence of bicuculline, the number of GDPs and GABA-mediated activity decreased significantly in comparison with before drug application at P8-9 (Supplementary Figure 1A and 1B) and P14-15 (Supplementary Figure 1C and 1D), respectively, in Syngap1 ${ }^{+/}$mice. No statistically significant difference was observed between with and without bicuculline at PND14-16 in WT. The experiments suggest that GABA has still excitatory action in Syngap1 ${ }^{+/}$. Disrupted activity within the DGGC could be due to impaired GABA-mediated tonic currents at P14-15. Using whole-cell patch-clamp from DGGC, we observed a significant GABA-mediated holding current component in WT (Wild Type) but not in Syngap $^{+/-}($Supplementary Figure 1E and 1F). Thus, a diminished strength of tonic inhibition due to altered GABAmediated activity may contribute to increased excitability during development in Syngap1 ${ }^{+/}$(Clement et al. 2012; Clement et al. 2013; Ozkan et al. 2014).

Disrupted GABA polarity switch in Syngap1 ${ }^{+/}$mice at P14-15

Dysfunctions of GABA-mediated effects on neuronal networks might be the result of an altered GABA reversal potential $\left(\mathrm{E}_{\mathrm{Cl}}{ }^{-}\right)$. GABA-mediated synaptic responses were elicited by stimulating the medial perforant pathway (MPP) in the presence of NMDAR and AMPAR blockers. Perforated whole-cell voltage-clamp recordings were conducted on DGGCs of WT and Syngap1 ${ }^{+/}$mice at different developmental stages. To determine the chloride reversal potential the neurons were voltage-clamped between $-100 \mathrm{mV}$ to $+40 \mathrm{mV}$ (Figure 1A and 1B). Analyses revealed a reduced $\mathrm{E}_{\mathrm{Cl}}^{-}$in DGGCs of P14-15-old Syngap 1 ${ }^{+/-}$mice (Figure 1C). A reduced $\mathrm{E}_{\mathrm{Cl}}^{-}$corresponds to excitatory action of GABAmediated synaptic transmission in Syngap $1^{+/}$. The altered $\mathrm{E}_{\mathrm{Cl}}{ }^{-}$of 2-week-old Syngap ${ }^{+/-}$mice will alter the direction of chloride flow, leading to reduced membrane potential and to GABA-mediated excitatory synaptic signals in the early stages of development leading to altered $\mathrm{E} / \mathrm{I}$.

309 Altered expression of NKCC1 and KCC2 during the development of Syngap1 ${ }^{+/}$mice:

310 NKCC1 and KCC2 regulate chloride homeostasis and excitatory-to-inhibitory shift of GABA during the development.

311 Therefore, it may indirectly regulate the E/I balance in the brain, which is known to be compromised in several 312 neurodevelopmental disorders (Blaesse et al. 2009; Ben-Ari et al. 2012; Gamba 2005; He et al. 2014; Duarte et al. 
2013; Banerjee et al. 2016; Deidda, Parrini, et al. 2015). Thus, we studied whether altered expression of NKCC1 and KCC2 in Syngap1 ${ }^{+-}$correlates with the observed functional differences regarding GABA-mediated actions. A significant difference in NKCC1 expression between Wild Type (WT) and Syngap1 ${ }^{+/}$at P8 was detectable using protein biochemical analysis (Figure 2A, and 2B). Notably, a compensatory increase in KCC2 expression was only detectable at P8 and not at P14 in Syngap1 ${ }^{+-}$(Figure 2C and 2D). At P14 Syngap1 1 ${ }^{+-}$, the KCC2 expression level was significantly low as compared with WT mice - a similar result as our immunofluorescence analyses (Figure 2E and 2F).

These results point towards an irregular expression of $\mathrm{NKCC1}$ and $\mathrm{KCC} 2$ in Syngap1 ${ }^{+/}$mice during their early developmental stages. An altered expression could potentially interrupt the $\mathrm{E}_{\mathrm{Cl}}$ and affect synaptic maturation and function. To further address a potential modulation on the level of $N k c c 1$, and $K c c 2$ gene expression, qPCR analyses were performed. The experiments did not reveal a change in the transcript levels within the hippocampus (Supplementary Figure 2). Thus, our findings suggest a disruption in the post-translational processing of NKCC1 and $\mathrm{KCC} 2$.

\section{BIO prevents behavioural deficits of Syngap ${ }^{+/}$mice:}

The results thus far demonstrated that a mutation at Syngapl caused a reduced neuronal network activity and inhibition due to disabling the switch of GABA polarity during the development of transgenic mice. GABAergic dysfunction is one of the hallmarks of ID/ASD and, thus, a vital candidate target to correct pathophysiological phenotypes. GSK3- $\beta$ is a well-known regulator of synaptic plasticity (Peineau et al. 2007; Liu et al. 2017). Small molecules such as 6BIO is a potent negative regulator of GSK3- $\beta$ and by crossing the blood-brain barrier it has been shown to be neuroprotective in an MPTP-based mouse model of Parkinson's disease. Accordingly, we sought whether administration of 6BIO might restore synaptic plasticity, $\mathrm{E}_{\mathrm{GABA}}$, and behavioural dysfunction in Syngap ${ }^{+/-}$mice. To this end, we studied the effects of 6BIO on mutant mice at three different age groups: Group I: P10-16 (critical period), Group II: P10-80 (critical period till adulthood), and Group III: P30-80 (adulthood; Figure 3A). Clement et al, 2012 (Clement et al. 2012) had demonstrated that the SYNGAP1 expression peaks at 14-16-day old mice where synaptic

337 function and dendritic spine morphology was reported at 14-16-day old Syngap $1^{+/}$mice. Further, in this study, they 338 have demonstrated that inducing heterozygous knock-out of Syngap1 in adults did not impact synaptic function contrary to knock-out of Syngap1 in P0. Correspondingly, our data shows that KCC2 expression and function ( $\left.\mathrm{E}_{\mathrm{GABA}}\right)$ 
is mainly disrupted at P14-16. Thus, we chose this period as a critical period of development as most of our study involved the hippocampus (critical period ends at 3-week) (Chakraborty, Vijay Kumar, and Clement 2021).

At P10-16, 6BIO treated Syngap $1^{+/-}$mice showed partial correction of hyperactivity in the open field test (OFT) (total distance; behaviour at P80; Supplementary Figure 3A). Interestingly, a stronger correction of hyperactivity was observed in mice at P16 (P10-80 age group, behaviour at P16; Figure 3B). The effect of 6BIO became less pronounced at P42 (P10-80 age group, behaviour at P16) (Figure 3C) and no rescue was observed at P30-80 (Figure 3D). The data suggest that $6 \mathrm{BIO}$ is most efficient when administered during the critical period of development. In addition, our experiments demonstrated that anxiety was corrected when behaviour performed at P16 (Figure 3E), P42 (Figure 3F), P10-16 age group (behaviour at P80; Supplementary Figure 3B), and a partial correction for P30-80 (Figure 3G) age group. Thus, in contrast to the previous conclusion, the data suggest that anxiety is more efficiently corrected when $6 \mathrm{BIO}$ is administered after the critical period of development.

To investigate the effect of 6BIO on memory, we performed a novel object recognition test (NOR; Familiar vs novel object). All behaviour tasks were performed at P80 (P10-16: Figure 4A; P10-80 Figure 4B; P30-80 Figure 4C). Remarkably, we found that 6BIO substantially restored memory performance in Syngap ${ }^{+/}{ }^{-}$mice.

Similar to NOR, a social novelty test (Social Interaction (SI) and Social preference (SP)) was performed for all age groups at P80 (P10-16: Figure 4D and 4G; P10-80: Figure 4E and 4H; P30-80: 4F and 4I). Our results suggested that the time spent with stranger-1 as compared to the empty jar for 6BIO treated Syngap1 ${ }^{+/}$mice were comparable to WT

357 levels in all age groups. However, we did not observe rescue in social preference for 6BIO treated Syngap $1^{+/}$mice in 358 the P10-16 group. Overall, our results suggest that 6BIO is effective in correcting the SI and SP deficits when 359 administered after a critical period of development in Syngap $1^{+/-}$mice.

\section{BIO induces a hyperpolarising shift in $\mathrm{E}_{\mathrm{GABA}}$ and restores LTP in Syngap1 $1^{+/}$mutation:}

361 Another primary attribute of ID/ASD is epileptic seizures which are observed in patients with SYNGAP1 haploinsufficiency (Hamdan et al. 2009) and reduced threshold to fluoroethyl in Syngap 1 ${ }^{+/}$mice (Clement et al. 2012). We observed an increased seizure threshold for the tonic-clonic seizure that matched WT levels in 6BIO administered Syngap $1^{+/}$mice at P30-80 (Figure 5A). We have summarised all the behaviour results in Table 2. The results indicate that rescuing GABAergic-synaptic function is fundamental in correcting behaviour in Syngap1 ${ }^{+/}$mice as LTP is 
disrupted in these adult mice (Ozkan et al. 2014). Considering the impact of Syngap ${ }^{+/-}$mutation as reported in other brain regions (Clement et al. 2012; Clement et al. 2013; Aceti et al. 2015; Ozkan et al. 2014), we performed $\mathrm{E}_{\mathrm{GABA}}$ from DGGC and LTP from the Schaffer-collateral commissural pathway to validate the effect of 6-BIO in different regions of the hippocampus.

We noticed that $\mathrm{E}_{\mathrm{Cl}}{ }^{-}$was corrected in $6 \mathrm{BIO}$ treated Syngap $1^{+/}$mice at P10-16 (Figure 5B); thus, could rectify increased excitation. Similarly, we observed that LTP was restored in 6BIO treated Syngap1 ${ }^{+/}$mice, particularly after the critical

372 period of development, correlating with our behaviour results (P10-80: Figure 5C; P30-80: Figure 5D). Our results

373 suggest small molecules such as $6 \mathrm{BIO}$ interventions, particularly after the critical period of development, can correct 374 functional and behavioural deficits in Syngap1 ${ }^{+/}$mice, indicating an opportunity for novel therapeutics to treat 375 neurodevelopmental disorders.

\section{Discussion:}

377 The interplay between GABAergic and Glutamatergic systems is indispensable for the formation, maturation, 378 refinement, and maintenance of synapses in the developing brain. Aberration in any of these processes results in neurodevelopmental and psychiatric disorders due to persistent changes in neuronal activity during development (BenAri et al. 1989; Cherubini, Gaiarsa, and Ben-Ari 1991; Owens et al. 1996; Rivera et al. 1999). Based on our results, we consider abnormal activation of neurons to occur upon GABA activation during developmental stages due to increased NKCC1 levels at P8 and a concomitant increase in KCC2 levels at P8 in Syngap1 ${ }^{+/}$, contributing to the increased intrinsic excitability (Clement et al. 2012; Kaila et al. 2014), similar to Fragile-X and Rett syndrome (Hinz, Torrella Barrufet, and Heine 2019; Banerjee et al. 2016). Increased KCC2 expression levels at P8 may further contribute to the intrinsic excitability, as demonstrated by an intriguing interaction with the $\mathrm{Na}^{+}-\mathrm{K}^{+}$-ATPase pump (Ikeda et al. 2004). Further, disrupted KCC2 expression may compensate for the increase in AMPA/NMDA ratio at 387 P14-15, causing increased excitability of the neurons at the developmental stage (2-week; Supplementary Figure 4), which is linked with synaptogenesis through KCC2 interactions with cytoskeletons such as 4.1, and ANKYRIN to regulate AMPAR clustering at the postsynapse (Chevy et al. 2015; Li et al. 2007; Llano et al. 2015; Chamma et al. 2012; Clement et al. 2012; Ikeda et al. 2004). As our results obtained by KCC2 expression at P14-15 corroborated with $\mathrm{E}_{\mathrm{GABA}}$ results (discussed later), and not $\mathrm{NKCC} 1$ expression, it prompted us to verify the $\mathrm{KCC} 2$ protein expression results by immunohistochemical analysis whose results complemented immunoblotting results. 
We propose that the irregular $\mathrm{E}_{\mathrm{GABA}}$ and subsequent depolarisation could lead to the disinhibition of GABA. An increase in the mIPSC amplitude at P14-15 (Clement et al. 2012) indicating elevated GABA receptors at the postsynapses, thus, compensating for the reduced expression of KCC2 at P14-15. Enhanced excitation through disinhibition is reflected by disrupted network activity mediated by GABA in P8-9 and P14-15, further corroborated by less tonic inhibition in 2-week-old Syngap1 ${ }^{+-}$mice. Less network activity in P14-15 indicates abnormality either in the compensatory effect of increased excitation due to disrupted GABA polarity switch or the decreased expression of KCC2 at the postsynapses in Syngap1 ${ }^{+/}$.

Our study, so far, has shown reduced GABA activity at P14-16 suggesting a possibility of less network activity (expanded data 1D) and decreased GABA-mediated activity in the presence of Bicuculline. This result indicates that GABA is still excitatory, which may fail to compensate for increased AMPA/NMDA ratio and mEPSC/mIPSC amplitude observed in Syngap1 ${ }^{+/}$mice at P14-15 (Clement et al. 2012; Ozkan et al. 2014). The depolarization observed in 2-week-old Syngap $1^{+/}$mice could be due to the disinhibition of GABA during early stages of development that results from impaired compensation of GABA, thereby, leading to altered E/I as observed in Syngap1 ${ }^{+/}$mice (Ozkan et al. 2014; Clement et al. 2012). Thus, we hypothesise that, based on our study and other published results, the cumulative impact of increased AMPA/NMDA, mEPSC, mIPSC, positive $\mathrm{E}_{\mathrm{GABA}}$, and decreased giant depolarisation potentials, potentially indicating disruption to the neuronal circuit activity at P14-16 leading to E/I imbalance, altered critical period of plasticity, impaired physiological, behavioural, and cognitive functions in the Syngap $1^{+/-}$mice.

411 Previous studies have demonstrated that the synaptic function and dendritic spine morphology deficits in Syngap $1^{+/}$ 412 mice were observed either over a single day or in a 2-3 day period within the critical period of development which is 413 comparable with our observation: hippocampus - critical period ends at 3 weeks; somatosensory - 7-9 days; mPFC 414 7-8 days; layer 5 - 30 days (Clement et al. 2012; Clement et al. 2013; Ozkan et al. 2014; Aceti et al. 2015). These 415 earlier studies strongly imply the stringent regulation of synaptic function and spine morphology during the critical 416 period of development by SYNGAP1 and how a mutation in this gene can disrupt it. Besides, similar to Syngap $1^{+/}$ 417 mice, disruption in the synaptic function and spine morphology in a comparable window of the critical period of development was reported in the Fragile-X syndrome mouse model (Harlow et al. 2010). Thus, these studies and our 
study indicate that the changes observed due to mutation in genes implicated in neurodevelopmental disorders regulate the critical period of development in a very short and accurate window of time.

421 Gating of the critical period of plasticity is dependent on optimal inhibition during the development, which in turn 422 determines the fate of inhibitory circuits in the brain (Hensch 2005; Hubener and Bonhoeffer 2014; Duarte et al. 2013; 423 Verma et al. 2019; He et al. 2014). Selective pharmacological modulations in GABAergic circuits during development have shown promising results in rescuing several physiological and behavioural deficits in ID/ASD models (Banerjee et al. 2016; Deidda, Parrini, et al. 2015; He et al. 2019; Braat and Kooy 2015), thus, a key candidate target for therapeutic intervention. Restoring the protein level of SYNGAP1 in adult stages restored synaptic function (LTP) but not behaviour, suggesting that these neurons are hard-wired during development (Ozkan et al. 2014). Nevertheless, genetic restoration of Syngap1 in the adult stages has restored some of the phenotypes, implying that not all deficits related to Syngap $1^{+/}$can be ascribed to neuronal circuit damage caused by aberrant neurodevelopment (Creson et al. 2019). A significant caveat evaluating the efficacy of drugs in pre-clinical models is either the lack of investigation on the effectiveness of drugs after the critical period (during hard-wiring) or the inability of the drug to restore function after the critical period (after hard-wiring) (He et al. 2019; McCamphill et al. 2020). Thus, concise therapeutics to correct deficiencies observed in Syngap1 ${ }^{+/}$-mediated ID/ASD is unfounded and provides the platform to find a candidate target for therapeutics that can restore phenotypes after the neurodevelopment period.

In various studies, targeting the GABAergic circuit has improved synaptic and behavioural deficits observed in the murine models of neurodevelopmental disorders (Banerjee et al. 2016; Deidda, Parrini, et al. 2015; He et al. 2019; Braat and Kooy 2015; Cellot and Cherubini 2014; Savardi et al. 2020; D'Hulst and Kooy 2007; Raveendran, Pressey, and Woodin 2020) and, thus, we speculated that restoring GABAergic function to WT levels can correct behavioural 439 deficits in Syngap1 ${ }^{+-}$mice. Our initial findings described the altered function of Chloride co-transporters (reversal potential of GABA) at P14-15 was restored when 6BIO was administered in Syngap1 ${ }^{+/-}$mice. In support of this, a recent study has shown that the application of BIO compound in a Rett syndrome model restored $\mathrm{E}_{\mathrm{GABA}}$, thus, restoring

442 behavioural function (Tang et al. 2019). This also led us to hypothesise that rectifying GABA function can correct 443 behavioural deficits in Syngap1 ${ }^{+/}$mice.

444 It is essential to understand whether the drug can correct behavioural deficits when administered in young adolescent stages, apart from when given during the critical period of development (P10-16). Based on the paradigm in Figure 
3A, P10-16 will address whether targeting the critical period alone would be sufficient to correct the phenotype with lasting effects in adult stages. P10-80 will answer whether the drug should be administered from the critical period of development and continue throughout adulthood. P30-80, the most crucial aspect of the drug discovery, would imply whether administration of the drug after a critical period of development corrects synaptic dysfunction and behavioural deficits, which remains a challenge to date. Most compounds can restore these functions when administered during the critical period of development (i.e., P10-16), which makes our study unique and different from the other published results.

We have recently shown that 6-bromoindirubin-3'-oxime (6BIO) is neuroprotective in an MPTP-based mouse model of Parkinson's disease, suggesting the potency to cross the blood-brain barrier and inhibit GSK-3 $\beta$ in neurons (Suresh et al. 2017). 6BIO administration in P30-80 (group III) has substantially restored functional (LTP, $\mathrm{E}_{\mathrm{GABA}}(\mathrm{P} 16)$ ) and behavioural deficits (sociability, memory, and anxiety) in Syngap 1 ${ }^{+/}$mice. However, hyperactivity was not corrected after the neurodevelopmental period suggesting that the target period is during the critical period of development. It appears that social isolation, social preference, and seizure threshold were not impacted by the hard wiring of the neuronal circuit during development as it is corrected in all three strategies, except in group I for SP. Primarily, we demonstrate that administration of 6BIO corrected memory deficits in all therapeutic strategies, particularly after the neurodevelopmental period.

462 Studies have demonstrated that the deficits observed in the Dentate gyrus (DG) in Syngap1 ${ }^{+-}$is recapitulated in the 463 CA1 region of the hippocampus (Clement et al. 2012). It is shown that LTP was reduced in the CA3-CA1 region while 464 the rest of the study was from the forebrain region of the brain (Ozkan et al. 2014). As demonstrated by previous 465 publications that the effect observed in DG is recapitulated in other parts of the hippocampus and also in other parts 466 of the brain such as the Barrel cortex and mPFC (Clement et al. 2013). Thus, these data demonstrate that the impact 467 of Syngap $1^{+-}$global and that prompted us to investigate the effect of 6 BIO in the DGGC and CA1 region of the 468 hippocampus. We believe that rectifying the $\mathrm{E}_{\mathrm{GABA}}$ may correct synaptic function and plasticity as optimal GABA 469 function is needed for suitable excitatory synaptic function leading to plasticity (Ormond and Woodin 2011; Larson 470 and Munkacsy 2015).

471 The reason we tested 6BIO is that studies from Franklin et al 2014, Hooper et al, 2007, and McCampil et al 2020 have 472 demonstrated that inhibiting GSK3ß attenuated LTP deficits observed in Fragile-X models (Franklin et al. 2014; 
473

474

475

476

477

478

479

Hooper et al. 2007; McCamphill et al. 2020), similar to what we observed in Syngap1 ${ }^{+/-}$model. However, these studies have not shown the level of rescue we observed in Syngap1 ${ }^{+/}$mice when 6 BIO was administered after the critical period of development (i.e., adolescent young adults). Despite this, there is a lack of clarity on the function of GSK3ß in modulating synaptic function. The reason, we believe, is that the pharmacological approaches and shRNA experiments (Liu et al. 2017) could be more acute compared to the conditional deletion, while the latter may induce the risk of measuring secondary effects of GSK- $3 \beta$ deletion. We agree that $6 \mathrm{BIO}$ may have other targets that can restore the synaptic function and behaviour deficits to WT levels which need to be explored but not in the scope of this study. However, these experiments are not in the scope of the current study.

In conclusion, our results are extremely encouraging as the administration of $6 \mathrm{BIO}$ after the neurodevelopmental period amended not only restored most of the phenotypes evaluated but also the synaptic functions. These results further emphasise the regime for therapeutic intervention should target the developmental period to protect the brain from the potential hard-wired circuit damage and to maximise the correction of phenotype. Our results denote a general mechanism involving GABAergic signalling prevailing in several neurodevelopmental disorders that can be corrected by small molecules such as $6 \mathrm{BIO}$. However, a major limitation of this compound is that it is not water-soluble and derivates of the compound that is water-soluble should be synthesised to administer it orally. Thus, our study supports the possibility that cognitive, emotional, and social symptoms that result from hard-wired neuronal circuit damage during development may still be corrected by late pharmacological intervention in adulthood.

\section{References:}

Aceti, M., T. K. Creson, T. Vaissiere, C. Rojas, W. C. Huang, Y. X. Wang, R. S. Petralia, D. T. Page, C. A. Miller, and G. Rumbaugh. 2015. 'Syngap1 haploinsufficiency damages a postnatal critical period of pyramidal cell structural maturation linked to cortical circuit assembly', Biol Psychiatry, 77: 805-15.

Banerjee, A., R. V. Rikhye, V. Breton-Provencher, X. Tang, C. Li, K. Li, C. A. Runyan, Z. Fu, R. Jaenisch, and M. Sur. 2016. 'Jointly reduced inhibition and excitation underlies circuit-wide changes in cortical processing in Rett syndrome', Proc Natl Acad Sci U S A, 113: E7287-E96.

Bear, M. F., K. M. Huber, and S. T. Warren. 2004. 'The mGluR theory of fragile X mental retardation', Trends Neurosci, 27: 370-7. 
Ben-Ari, Y. 2002. 'Excitatory actions of gaba during development: the nature of the nurture', Nat Rev Neurosci, 3 : 728-39.

Ben-Ari, Y., E. Cherubini, R. Corradetti, and J. L. Gaiarsa. 1989. 'Giant synaptic potentials in immature rat CA3 hippocampal neurones', J Physiol, 416: 303-25.

Ben-Ari, Y., I. Khalilov, K. T. Kahle, and E. Cherubini. 2012. 'The GABA excitatory/inhibitory shift in brain maturation and neurological disorders', Neuroscientist, 18: 467-86.

Berryer, M. H., F. F. Hamdan, L. L. Klitten, R. S. Moller, L. Carmant, J. Schwartzentruber, L. Patry, S. Dobrzeniecka, D. Rochefort, M. Neugnot-Cerioli, J. C. Lacaille, Z. Niu, C. M. Eng, Y. Yang, S. Palardy, C. Belhumeur, G. A. Rouleau, N. Tommerup, L. Immken, M. H. Beauchamp, G. S. Patel, J. Majewski, M. A. Tarnopolsky, K. Scheffzek, H. Hjalgrim, J. L. Michaud, and G. Di Cristo. 2013. 'Mutations in SYNGAP1 cause intellectual disability, autism, and a specific form of epilepsy by inducing haploinsufficiency', Hum Mutat, 34: 385-94.

Blaesse, P., M. S. Airaksinen, C. Rivera, and K. Kaila. 2009. 'Cation-chloride cotransporters and neuronal function', Neuron, 61: 820-38.

Blaesse, P., I. Guillemin, J. Schindler, M. Schweizer, E. Delpire, L. Khiroug, E. Friauf, and H. G. Nothwang. 2006. 'Oligomerization of KCC2 correlates with development of inhibitory neurotransmission', J Neurosci, 26: 10407-19.

Bliss, T. V., and G. L. Collingridge. 1993. 'A synaptic model of memory: long-term potentiation in the hippocampus', Nature, 361: 31-9.

Booth, C. A., J. T. Brown, and A. D. Randall. 2014. 'Neurophysiological modification of CA1 pyramidal neurons in a transgenic mouse expressing a truncated form of disrupted-in-schizophrenia 1', Eur J Neurosci, 39: 107490.

Braat, S., and R. F. Kooy. 2015. 'The GABAA Receptor as a Therapeutic Target for Neurodevelopmental Disorders', Neuron, 86: 1119-30.

Cellot, G., and E. Cherubini. 2014. 'GABAergic signaling as therapeutic target for autism spectrum disorders', Front Pediatr, 2: 70.

Chakraborty, R., M. J. Vijay Kumar, and J. P. Clement. 2021. 'Critical aspects of neurodevelopment', Neurobiol Learn Mem, 180: 107415. 
Chamma, I., Q. Chevy, J. C. Poncer, and S. Levi. 2012. 'Role of the neuronal K-Cl co-transporter KCC2 in inhibitory and excitatory neurotransmission', Front Cell Neurosci, 6: 5.

Cherubini, E., J. L. Gaiarsa, and Y. Ben-Ari. 1991. 'GABA: an excitatory transmitter in early postnatal life', Trends Neurosci, 14: 515-9.

Chevy, Q., M. Heubl, M. Goutierre, S. Backer, I. Moutkine, E. Eugene, E. Bloch-Gallego, S. Levi, and J. C. Poncer. 2015. 'KCC2 Gates Activity-Driven AMPA Receptor Traffic through Cofilin Phosphorylation', J Neurosci, 35: $15772-86$.

Clement, J. P., M. Aceti, T. K. Creson, E. D. Ozkan, Y. Shi, N. J. Reish, A. G. Almonte, B. H. Miller, B. J. Wiltgen, C. A. Miller, X. Xu, and G. Rumbaugh. 2012. 'Pathogenic SYNGAP1 mutations impair cognitive development by disrupting maturation of dendritic spine synapses', Cell, 151: 709-23.

Clement, J. P., E. D. Ozkan, M. Aceti, C. A. Miller, and G. Rumbaugh. 2013. 'SYNGAP1 links the maturation rate of excitatory synapses to the duration of critical-period synaptic plasticity', J Neurosci, 33: 10447-52.

Cope, D. W., G. Di Giovanni, S. J. Fyson, G. Orban, A. C. Errington, M. L. Lorincz, T. M. Gould, D. A. Carter, and V. Crunelli. 2009. 'Enhanced tonic GABAA inhibition in typical absence epilepsy', Nat Med, 15: 1392-8.

Creson, T. K., C. Rojas, E. Hwaun, T. Vaissiere, M. Kilinc, A. Jimenez-Gomez, J. L. Holder, Jr., J. Tang, L. L. Colgin, C. A. Miller, and G. Rumbaugh. 2019. 'Re-expression of SynGAP protein in adulthood improves translatable measures of brain function and behavior', Elife, 8 .

D'Hulst, C., and R. F. Kooy. 2007. 'The GABAA receptor: a novel target for treatment of fragile X?', Trends Neurosci, 30: 425-31.

Deidda, G., M. Allegra, C. Cerri, S. Naskar, G. Bony, G. Zunino, Y. Bozzi, M. Caleo, and L. Cancedda. 2015. 'Early depolarizing GABA controls critical-period plasticity in the rat visual cortex', Nat Neurosci, 18: 87-96.

Deidda, G., M. Parrini, S. Naskar, I. F. Bozarth, A. Contestabile, and L. Cancedda. 2015. 'Reversing excitatory GABAAR signaling restores synaptic plasticity and memory in a mouse model of Down syndrome', Nat Med, 21: 318-26.

Duarte, S. T., J. Armstrong, A. Roche, C. Ortez, A. Perez, M. O'Callaghan Mdel, A. Pereira, F. Sanmarti, A. Ormazabal, R. Artuch, M. Pineda, and A. Garcia-Cazorla. 2013. 'Abnormal expression of cerebrospinal fluid cation chloride cotransporters in patients with Rett syndrome', PLoS One, 8: e68851. 
Franklin, A. V., M. K. King, V. Palomo, A. Martinez, L. L. McMahon, and R. S. Jope. 2014. 'Glycogen synthase kinase-3 inhibitors reverse deficits in long-term potentiation and cognition in fragile X mice', Biol Psychiatry, 75: 198-206.

Gamba, G. 2005. 'Molecular physiology and pathophysiology of electroneutral cation-chloride cotransporters', Physiol Rev, 85: 423-93.

Griguoli, M., and E. Cherubini. 2017. 'Early Correlated Network Activity in the Hippocampus: Its Putative Role in Shaping Neuronal Circuits', Front Cell Neurosci, 11: 255.

Guo, X., P. J. Hamilton, N. J. Reish, J. D. Sweatt, C. A. Miller, and G. Rumbaugh. 2009. 'Reduced expression of the NMDA receptor-interacting protein SynGAP causes behavioral abnormalities that model symptoms of Schizophrenia', Neuropsychopharmacology, 34: 1659-72.

Hamdan, F. F., H. Daoud, A. Piton, J. Gauthier, S. Dobrzeniecka, M. O. Krebs, R. Joober, J. C. Lacaille, A. Nadeau, J. M. Milunsky, Z. Wang, L. Carmant, L. Mottron, M. H. Beauchamp, G. A. Rouleau, and J. L. Michaud. 2011. 'De novo SYNGAP1 mutations in nonsyndromic intellectual disability and autism', Biol Psychiatry, 69: 898-901.

Hamdan, F. F., J. Gauthier, D. Spiegelman, A. Noreau, Y. Yang, S. Pellerin, S. Dobrzeniecka, M. Cote, E. PerreauLinck, L. Carmant, G. D'Anjou, E. Fombonne, A. M. Addington, J. L. Rapoport, L. E. Delisi, M. O. Krebs, F. Mouaffak, R. Joober, L. Mottron, P. Drapeau, C. Marineau, R. G. Lafreniere, J. C. Lacaille, G. A. Rouleau, J. L. Michaud, and Group Synapse to Disease. 2009. 'Mutations in SYNGAP1 in autosomal nonsyndromic mental retardation', $N$ Engl J Med, 360: 599-605.

Harlow, E. G., S. M. Till, T. A. Russell, L. S. Wijetunge, P. Kind, and A. Contractor. 2010. 'Critical period plasticity is disrupted in the barrel cortex of FMR1 knockout mice', Neuron, 65: 385-98.

He, Q., E. D. Arroyo, S. N. Smukowski, J. Xu, C. Piochon, J. N. Savas, C. Portera-Cailliau, and A. Contractor. 2019. 'Critical period inhibition of NKCC1 rectifies synapse plasticity in the somatosensory cortex and restores adult tactile response maps in fragile X mice', Mol Psychiatry, 24: 1732-47.

He, Q., T. Nomura, J. Xu, and A. Contractor. 2014. 'The developmental switch in GABA polarity is delayed in fragile X mice', J Neurosci, 34: 446-50.

Hensch, T. K. 2005. 'Critical period plasticity in local cortical circuits', Nat Rev Neurosci, 6: 877-88. 
Hinz, L., J. Torrella Barrufet, and V. M. Heine. 2019. 'KCC2 expression levels are reduced in post mortem brain tissue of Rett syndrome patients', Acta Neuropathol Commun, 7: 196.

Hooper, C., V. Markevich, F. Plattner, R. Killick, E. Schofield, T. Engel, F. Hernandez, B. Anderton, K. Rosenblum, T. Bliss, S. F. Cooke, J. Avila, J. J. Lucas, K. P. Giese, J. Stephenson, and S. Lovestone. 2007. 'Glycogen synthase kinase-3 inhibition is integral to long-term potentiation', Eur J Neurosci, 25: 81-6.

Hubener, M., and T. Bonhoeffer. 2014. 'Neuronal plasticity: beyond the critical period', Cell, 159: 727-37.

Hyde, T. M., B. K. Lipska, T. Ali, S. V. Mathew, A. J. Law, O. E. Metitiri, R. E. Straub, T. Ye, C. Colantuoni, M. M. Herman, L. B. Bigelow, D. R. Weinberger, and J. E. Kleinman. 2011. 'Expression of GABA signaling molecules KCC2, NKCC1, and GAD1 in cortical development and schizophrenia', J Neurosci, 31: 1108895.

Ikeda, K., H. Onimaru, J. Yamada, K. Inoue, S. Ueno, T. Onaka, H. Toyoda, A. Arata, T. O. Ishikawa, M. M. Taketo, A. Fukuda, and K. Kawakami. 2004. 'Malfunction of respiratory-related neuronal activity in $\mathrm{Na}+, \mathrm{K}+-$ ATPase alpha2 subunit-deficient mice is attributable to abnormal Cl- homeostasis in brainstem neurons', $J$ Neurosci, 24: 10693-701.

Jeyabalan, N., and J. P. Clement. 2016. 'SYNGAP1: Mind the Gap', Front Cell Neurosci, 10: 32.

Kadiyala, S. B., D. Papandrea, B. J. Herron, and R. J. Ferland. 2014. 'Segregation of seizure traits in C57 black mouse substrains using the repeated-flurothyl model', PLoS One, 9: e90506.

Kaila, K., T. J. Price, J. A. Payne, M. Puskarjov, and J. Voipio. 2014. 'Cation-chloride cotransporters in neuronal development, plasticity and disease', Nat Rev Neurosci, 15: 637-54.

Kepecs, A., and G. Fishell. 2014. 'Interneuron cell types are fit to function', Nature, 505: 318-26.

Kilinc, M., T. Creson, C. Rojas, M. Aceti, J. Ellegood, T. Vaissiere, J. P. Lerch, and G. Rumbaugh. 2018. 'Speciesconserved SYNGAP1 phenotypes associated with neurodevelopmental disorders', Mol Cell Neurosci, 91: $140-50$.

Kimura, Y., M. Akahira-Azuma, N. Harada, Y. Enomoto, Y. Tsurusaki, and K. Kurosawa. 2018. 'Novel SYNGAP1 variant in a patient with intellectual disability and distinctive dysmorphisms', Congenit Anom (Kyoto), 58: $188-90$.

Komiyama, N. H., A. M. Watabe, H. J. Carlisle, K. Porter, P. Charlesworth, J. Monti, D. J. Strathdee, C. M. O'Carroll, S. J. Martin, R. G. Morris, T. J. O'Dell, and S. G. Grant. 2002. 'SynGAP regulates ERK/MAPK signaling, 
synaptic plasticity, and learning in the complex with postsynaptic density 95 and NMDA receptor', $J$ Neurosci, 22: 9721-32.

610 Larson, J., and E. Munkacsy. 2015. 'Theta-burst LTP', Brain Res, 1621: 38-50.

611 Leger, M., A. Quiedeville, V. Bouet, B. Haelewyn, M. Boulouard, P. Schumann-Bard, and T. Freret. 2013. 'Object recognition test in mice', Nat Protoc, 8: 2531-7.

Li, H., S. Khirug, C. Cai, A. Ludwig, P. Blaesse, J. Kolikova, R. Afzalov, S. K. Coleman, S. Lauri, M. S. Airaksinen, K. Keinanen, L. Khiroug, M. Saarma, K. Kaila, and C. Rivera. 2007. 'KCC2 interacts with the dendritic cytoskeleton to promote spine development', Neuron, 56: 1019-33.

Liu, E., A. J. Xie, Q. Zhou, M. Li, S. Zhang, S. Li, W. Wang, X. Wang, Q. Wang, and J. Z. Wang. 2017. 'GSK-3beta deletion in dentate gyrus excitatory neuron impairs synaptic plasticity and memory', Sci Rep, 7: 5781.

Llano, O., S. Smirnov, S. Soni, A. Golubtsov, I. Guillemin, P. Hotulainen, I. Medina, H. G. Nothwang, C. Rivera, and Biol, 209: 671-86.

Lueptow, L. M. 2017. 'Novel Object Recognition Test for the Investigation of Learning and Memory in Mice', J Vis Exp.

Madhwal, S., M. Shin, A. Kapoor, M. Goyal, M. K. Joshi, P. M. Ur Rehman, K. Gor, J. Shim, and T. Mukherjee. 2020. 'Metabolic control of cellular immune-competency by odors in Drosophila', Elife, 9.

McCamphill, P. K., L. J. Stoppel, R. K. Senter, M. C. Lewis, A. J. Heynen, D. C. Stoppel, V. Sridhar, K. A. Collins, X. Shi, J. Q. Pan, J. Madison, J. R. Cottrell, K. M. Huber, E. M. Scolnick, E. B. Holson, F. F. Wagner, and M. F. Bear. 2020. 'Selective inhibition of glycogen synthase kinase 3alpha corrects pathophysiology in a mouse model of fragile X syndrome', Sci Transl Med, 12.

Meijer, L., A. L. Skaltsounis, P. Magiatis, P. Polychronopoulos, M. Knockaert, M. Leost, X. P. Ryan, C. A. Vonica, A. Brivanlou, R. Dajani, C. Crovace, C. Tarricone, A. Musacchio, S. M. Roe, L. Pearl, and P. Greengard. 2003. 'GSK-3-selective inhibitors derived from Tyrian purple indirubins', Chem Biol, 10: 1255-66.

Min, W. W., C. J. Yuskaitis, Q. Yan, C. Sikorski, S. Chen, R. S. Jope, and R. P. Bauchwitz. 2009. 'Elevated glycogen synthase kinase-3 activity in Fragile X mice: key metabolic regulator with evidence for treatment potential', Neuropharmacology, 56: 463-72. 
Mines, M. A., and R. S. Jope. 2011. 'Glycogen synthase kinase-3: a promising therapeutic target for fragile $\mathrm{x}$ syndrome', Front Mol Neurosci, 4: 35.

Muhia, M., B. K. Yee, J. Feldon, F. Markopoulos, and I. Knuesel. 2010. 'Disruption of hippocampus-regulated behavioural and cognitive processes by heterozygous constitutive deletion of SynGAP', Eur J Neurosci, 31: $529-43$

Nakajima, R., K. Takao, S. Hattori, H. Shoji, N. H. Komiyama, S. G. N. Grant, and T. Miyakawa. 2019. 'Comprehensive behavioral analysis of heterozygous Syngap1 knockout mice', Neuropsychopharmacol Rep, 39: 223-37.

Ormond, J., and M. A. Woodin. 2011. 'Disinhibition-Mediated LTP in the Hippocampus is Synapse Specific', Front Cell Neurosci, 5: 17.

Owens, D. F., L. H. Boyce, M. B. Davis, and A. R. Kriegstein. 1996. 'Excitatory GABA responses in embryonic and neonatal cortical slices demonstrated by gramicidin perforated-patch recordings and calcium imaging', $J$ Neurosci, 16: 6414-23.

Ozkan, E. D., T. K. Creson, E. A. Kramar, C. Rojas, R. R. Seese, A. H. Babyan, Y. Shi, R. Lucero, X. Xu, J. L. Noebels, C. A. Miller, G. Lynch, and G. Rumbaugh. 2014. 'Reduced cognition in Syngap1 mutants is caused by isolated damage within developing forebrain excitatory neurons', Neuron, 82: 1317-33.

Peineau, S., C. Taghibiglou, C. Bradley, T. P. Wong, L. Liu, J. Lu, E. Lo, D. Wu, E. Saule, T. Bouschet, P. Matthews, J. T. Isaac, Z. A. Bortolotto, Y. T. Wang, and G. L. Collingridge. 2007. 'LTP inhibits LTD in the hippocampus via regulation of GSK3beta', Neuron, 53: 703-17.

Penzes, P., M. E. Cahill, K. A. Jones, J. E. VanLeeuwen, and K. M. Woolfrey. 2011. 'Dendritic spine pathology in neuropsychiatric disorders', Nat Neurosci, 14: 285-93.

Polychronopoulos, P., P. Magiatis, A. L. Skaltsounis, V. Myrianthopoulos, E. Mikros, A. Tarricone, A. Musacchio, S. M. Roe, L. Pearl, M. Leost, P. Greengard, and L. Meijer. 2004. 'Structural basis for the synthesis of indirubins as potent and selective inhibitors of glycogen synthase kinase-3 and cyclin-dependent kinases', $J$ Med Chem, 47: 935-46.

Raveendran, V. A., J. C. Pressey, and M. A. Woodin. 2020. 'A Novel Small Molecule Targets NKCC1 To Restore Synaptic Inhibition', Trends Pharmacol Sci, 41: 897-99. 
Rivera, C., J. Voipio, and K. Kaila. 2005. 'Two developmental switches in GABAergic signalling: the K+-Clcotransporter KCC2 and carbonic anhydrase CAVII', J Physiol, 562: 27-36.

Rivera, C., J. Voipio, J. A. Payne, E. Ruusuvuori, H. Lahtinen, K. Lamsa, U. Pirvola, M. Saarma, and K. Kaila. 1999. 'The K+/Cl- co-transporter KCC2 renders GABA hyperpolarizing during neuronal maturation', Nature, 397: $251-5$.

Salcedo-Tello, P., A. Ortiz-Matamoros, and C. Arias. 2011. 'GSK3 Function in the Brain during Development, Neuronal Plasticity, and Neurodegeneration', Int J Alzheimers Dis, 2011: 189728.

Samoriski, G. M., and C. D. Applegate. 1997. 'Repeated generalized seizures induce time-dependent changes in the behavioral seizure response independent of continued seizure induction', J Neurosci, 17: 5581-90.

Savardi, A., M. Borgogno, R. Narducci, G. La Sala, J. A. Ortega, M. Summa, A. Armirotti, R. Bertorelli, A. Contestabile, M. De Vivo, and L. Cancedda. 2020. 'Discovery of a Small Molecule Drug Candidate for Selective NKCC1 Inhibition in Brain Disorders', Chem, 6: 2073-96.

Shim, J., T. Mukherjee, and U. Banerjee. 2012. 'Direct sensing of systemic and nutritional signals by haematopoietic progenitors in Drosophila', Nat Cell Biol, 14: 394-400.

Sipila, S. T., K. Huttu, I. Soltesz, J. Voipio, and K. Kaila. 2005. 'Depolarizing GABA acts on intrinsically bursting pyramidal neurons to drive giant depolarizing potentials in the immature hippocampus', $J$ Neurosci, 25: 52809.

Suresh, S. N., A. K. Chavalmane, V. Dj, H. Yarreiphang, S. Rai, A. Paul, J. P. Clement, P. A. Alladi, and R. Manjithaya. 2017. 'A novel autophagy modulator 6-Bio ameliorates SNCA/alpha-synuclein toxicity', Autophagy, 13: 1221-34.

Tang, X., J. Drotar, K. Li, C. D. Clairmont, A. S. Brumm, A. J. Sullins, H. Wu, X. S. Liu, J. Wang, N. S. Gray, M. Sur, and R. Jaenisch. 2019. 'Pharmacological enhancement of KCC2 gene expression exerts therapeutic effects on human Rett syndrome neurons and Mecp2 mutant mice', Sci Transl Med, 11.

Verma, V., A. Paul, A. Amrapali Vishwanath, B. Vaidya, and J. P. Clement. 2019. 'Understanding intellectual disability and autism spectrum disorders from common mouse models: synapses to behaviour', Open Biol, 9: 180265.

Vlaskamp, D. R. M., B. J. Shaw, R. Burgess, D. Mei, M. Montomoli, H. Xie, C. T. Myers, M. F. Bennett, W. XiangWei, D. Williams, S. M. Maas, A. S. Brooks, G. M. S. Mancini, Imbh van de Laar, J. M. van Hagen, 
T. L. Ware, R. I. Webster, S. Malone, S. F. Berkovic, R. M. Kalnins, F. Sicca, G. C. Korenke, C. M. A. van Ravenswaaij-Arts, M. S. Hildebrand, H. C. Mefford, Y. Jiang, R. Guerrini, and I. E. Scheffer. 2019. 'SYNGAP1 encephalopathy: A distinctive generalized developmental and epileptic encephalopathy', Neurology, 92: e96-e107.

Vougogiannopoulou, K., and A. L. Skaltsounis. 2012. 'From Tyrian purple to kinase modulators: naturally halogenated indirubins and synthetic analogues', Planta Med, 78: 1515-28.

Yao, H. B., P. C. Shaw, C. C. Wong, and D. C. Wan. 2002. 'Expression of glycogen synthase kinase-3 isoforms in mouse tissues and their transcription in the brain', J Chem Neuroanat, 23: 291-7.

Figure legends:

Figure 1: Neurons of Syngap1 ${ }^{+/-}$mice show a shift in chloride reversal potential $\left(\mathbf{E}_{\mathrm{Cl}}{ }^{-}\right)$at $\mathrm{P14}$-15:

A) Left, Evoked representative $\mathrm{Cl}^{-}$mediated current traces at the indicated holding potentials of a Gramicidin-based perforated voltage-clamp experiment. Right, The graph to the right summarises the relationship of holding potential $(\mathrm{mV})$ to current amplitude for one representative experiment and depicts the trend as a linear fit curve. The experiments were conducted at P14-15 in WT mice. B) Same as A but in P14-15 Syngap1 ${ }^{+-}$. C) The graph summarises the reversal potentials of GABA receptor-mediated $\mathrm{Cl}^{-}$current $\left(\mathrm{E}_{\mathrm{Cl}}{ }^{-}\right)$in WT as well as Syngap1 ${ }^{+/}$at the indicated postnatal ages. P4-5: WT: N=6, n=7, 35 \pm 1.37 ; Syngap1 ${ }^{+/}: \mathrm{N}=4, \mathrm{n}=7,48 \pm 3$, (NS: $\left.\mathrm{p}>0.05\right)$; P7: WT: N=3, n= 4, 44 \pm 2.78 ; Syngap1 ${ }^{+/}$ $\mathrm{N}=3, \mathrm{n}=5,47 \pm 3$,(NS: $\mathrm{p}>0.05)$; P8: WT N=5, $\mathrm{n}=6,46 \pm 1 ;$ Syngap1 $^{+/}: \mathrm{N}=4, \mathrm{n}=8,51 \pm 4.04, \mathrm{NS}: \mathrm{p}>0.05$; P14-15: WT: $\mathrm{N}=3, \mathrm{n}=7 ;$ Syngap $^{+/}: \mathrm{N}=4, \mathrm{n}=6,{ }^{* * *} \mathrm{p}<0.001 ; \mathrm{P} 21-23 \mathrm{WT}, \mathrm{N}=4, \mathrm{n}=6,65 \pm 2 ;$ Syngap 1 $^{+/}: \mathrm{N}=3, \mathrm{n}=7,64 \pm 2, \mathrm{NS}: \mathrm{p}>0.05$; $\mathrm{P} \geq 90$ : WT: N=7, $\mathrm{n}=15,68 \pm 1.53$; Syngap1 ${ }^{+/}, \mathrm{N}=5, \mathrm{n}=9,71 \pm 2.18$, NS: $\mathrm{p}>0.05 . \mathrm{F}{ }_{(5,76)}=6.83, \mathrm{p}<0.0001$ for the interaction. Data are presented as single data points and means \pm SEM. N: number of mice, n: number of cells. Twoway ANOVA, Tukey's multiple comparisons test.

Figure 2: Age-dependent expression levels of NKCC1 and KCC2 $\mathrm{Cl}^{-}$co-transporters in WT and Syngap1 ${ }^{+/}$ mice:

A) Top, Representative NKCC1 immunoblots at P8 are depicted. B) Bottom, line graph summarizes NKCC1 expression levels at different post-natal ages for WT as well as Syngap1 ${ }^{+/}$. P4-5 (WT) N=7, 0.48 \pm 0.1 , $\left(\right.$ Syngap $^{+/}$) $\mathrm{N}=11,0.58 \pm 0.03$ (p: 0.1320); P7 (WT) N=7, $1 \pm 0.1$, Syngap1 $^{+-}$) N=8, $0.87 \pm 0.1228$ (p>0.05); P8 (WT) N=6, 
$0.72 \pm 0.05,\left(\right.$ Syngap 1 $\left.^{+-}\right) \mathrm{N}=6,0.98 \pm 0.09\left({ }^{*} \mathrm{p}<0.05\right) ; \mathrm{P} 14-15$ (WT) N=13, 0.8 \pm 0.05 , $\left(\right.$ Syngap1 $\left.^{+-}\right) \mathrm{N}=10,0.8 \pm 0.07$

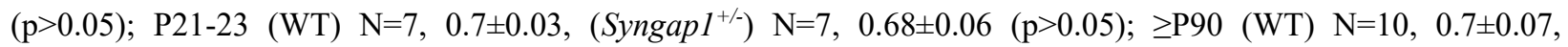
$\left(\right.$ Syngap $\left.^{+/}\right) \mathrm{N}=10,0.79 \pm 0.08(\mathrm{p}>0.05) . \mathrm{F}(5,90)=1.48, \mathrm{p}=0.2027$ for the interaction. C) Top, Representative P14-15 immunoblots for KCC2 are shown. D) Bottom, line graph summarizes KCC2 expression level during development in WT as well as Syngap1 ${ }^{+/}$. (P4-5 (WT) N=9, 2.3 \pm 0.18 , Syngap 1 $^{+/}$) N=9, 2.8 \pm 0.18 (p>0.05); P7 (WT) N=8, 2.4 \pm 0.17 , $\left(\right.$ Syngap $\left.^{+}\right) \mathrm{N}=8,2 \pm 0.17(\mathrm{p}>0.05) ; \mathrm{P} 8(\mathrm{WT}) \mathrm{N}=5,3.7 \pm 0.12,\left(\right.$ Syngap $\left.^{+-}\right) \mathrm{N}=6,6.2 \pm 0.79(* * \mathrm{p}<0.01) ; \mathrm{P} 14-15$ (WT) $\mathrm{N}=7,5.717 \pm 0.7434,\left(\right.$ Syngap 1 $\left.^{+-}\right) \mathrm{N}=8,2 \pm 0.3(* * * \mathrm{p}<0.001) ; \mathrm{P} 21-23$ (WT) N=7, 4.872 $\pm 0.6442,\left(\right.$ Syngap $\left.^{+/}\right) \mathrm{N}=7$, $3.4 \pm 0.1(\mathrm{p}>0.05) ; \geq P 90$ (WT) N=10, 2.3 $\pm 0.2,\left(\right.$ Syngap $\left.^{+/}\right) \mathrm{N}=10,2.8 \pm 0.2(\mathrm{p}>0.05) . \mathrm{F}_{(5,82)}=14.46, \mathrm{p}<0.0001$ for the interaction. Data are presented as mean \pm SEM. N: number of mice. Two-way ANOVA, Tukey's multiple comparisons test. E) Representative immunofluorescence images depicting SYNGAP1 and KCC2 localisation and expression pattern in hippocampus region (DGGC for all age group and sections) in WT and Syngap1 ${ }^{+-}$mice at P8, 14-15 and $\geq 90$. White arrows indicate punctate expression pattern of KCC2 and SYNGAP1. Blue colour represents the Hoescht staining of the nucleus, green coloured puncta are of SYNGAP1 protein, and KCC2 puncta surrounding soma and dendrites are presented in red. F) Bar graph representing the integrated density of WT and Syngap1 ${ }^{+/}$in the individual age group is shown in front of the respective panel of P8, 14-15 and $\geq 90$. P8 (WT) n=4, 1165283 \pm 64324 , (Syngap $1^{+/}$ ) $\mathrm{n}=5, \quad 1426211 \pm 47106\left({ }^{*} \mathrm{p}<0.05\right) ; \mathrm{P} 14-15$ (WT) $\mathrm{n}=7,1202925 \pm 43917,\left(\right.$ Syngap $\left.^{+/-}\right) \mathrm{n}=6,766779 \pm 18128$ $\left({ }^{* * *} \mathrm{p}<0.001\right) ; \mathrm{P} \geq 90(\mathrm{WT}) \mathrm{n}=6,1697380 \pm 22155,\left(\right.$ Syngap1 $\left.^{+/}\right) \mathrm{n}=8,1656486 \pm 32631(\mathrm{p}>0.05)$. Scale bar $=20 \mu \mathrm{m}$. Data are presented as mean \pm SEM. Unpaired $t$-test, n: number of sections.

\section{Figure 3: 6BIO corrects hyperactivity and anxiety deficits in Syngap ${ }^{+/-}$}

A) Chart depicting the regime for $6 \mathrm{BIO}$ intraperitoneal injection $(5 \mathrm{mg} / \mathrm{kg})$ and categorisation of age groups. B) Total distance travelled by the mice in open field chamber was grouped and shown as individual data points for P10-80 where behaviour was done at P16 WT-Vehicle: N=20; Syngap1 ${ }^{+/-}$-Vehicle: N=11; WT-6BIO: N=16; Syngap1 ${ }^{+/}-$ 6BIO: $\left.\mathrm{N}=14, \mathrm{~F}_{(1,57)}=14.83, \mathrm{p}=0.0003, \mathrm{C}\right) \mathrm{P} 10-80$ where behaviour was done at $\mathrm{P} 42$, WT-Vehicle: $\mathrm{N}=17$; Syngap $1^{+/}$ -Vehicle: N=9; WT-6BIO: N=15; Syngap 1 ${ }^{+-}-6 \mathrm{BIO}: \mathrm{N}=9, \mathrm{~F}_{(1,44)}=4.752, \mathrm{p}=0.0347$, and D) P30-80, WT-Vehicle: N=14; Syngap 1 ${ }^{+/-V e h i c l e: ~ N=14 ; ~ W T-6 B I O: ~ N=16 ; ~ S y n g a p 1 ~}{ }^{+/-}-6 \mathrm{BIO}: \mathrm{N}=16, \mathrm{~F}_{(1,56)}=0.4686, \mathrm{p}=0.4965$. E) Number of entries in the centre as a measure of anxiety was grouped and shown as individual data points for P10-80 where behaviour was done at P16, WT-Vehicle: N=20; Syngap1 ${ }^{+/-}$-Vehicle: N=11; WT-6BIO: N=16; Syngap1 ${ }^{+/}-$ 
6BIO: $\left.\mathrm{N}=14, \mathrm{~F}_{(1,57)}=18.01, \mathrm{p}<0.0001, \mathrm{~F}\right) \mathrm{P} 10-80$ where behaviour was done at P42, WT-Vehicle: N=18; Syngap1 ${ }^{+/}$ -Vehicle: N=10; WT-6BIO: N=15; Syngap1 1 -_6BIO: N=11, $\mathrm{F}_{(1,50)}=2.194, \mathrm{p}=0.1449$, and G) P30-80, WT-Vehicle: N=13; Syngap1 ${ }^{+/}-$Vehicle: N=12; WT-6BIO: N=15; Syngap1 ${ }^{+/}-6 \mathrm{BIO}: \mathrm{N}=18, \mathrm{~F}_{(1,54)}=6.002$, p=0.0176. Two-way ANOVA, Tukey's multiple comparisons test.

Figure 4: 6BIO corrects memory recognition and sociability deficits in Syngap ${ }^{+/}$particularly in the postcritical period of development:

A) Discrimination index was plotted as the measure of recognition memory and plotted as individual data points for P10-16 where behavior was done at P80, WT-Vehicle: N=11; Syngap1 ${ }^{+/-}-$Vehicle: N=6; WT-6BIO: N=9; Syngap1 ${ }^{+/}$ -6BIO: N=14, $\mathrm{F}_{(1,36)}=14.76, \mathrm{p}=0.0005$, B) P10-80 where behavior was done at P80, WT-Vehicle: N=16; Syngap1 ${ }^{+/}$ -Vehicle: $\mathrm{N}=7$; WT-6BIO: $\mathrm{N}=11 ; \% \mathrm{~N}=10, \mathrm{~F}_{(1,40)}=1.982, \mathrm{p}=0.1669$, and C) $\mathrm{P} 30-80$ where behavior was done at $\mathrm{P} 80$, WT-Vehicle: N=8; Syngap 1+--Vehicle: N=7; WT-6BIO: N=9; Syngap 1 ${ }^{+/-6 B I O: ~ N=15, ~ F ~}(1,35)=7.687, \mathrm{p}=0.0089$. Social interaction and preference was evaluated as time spent with stranger1 as compared to empty jar, and time spent with stanger2 as compared to stranger1 respectively for D) P10-16 where behavior was done at P80, WT-Vehicle: N=12; Syngap 1 ${ }^{+--V e h i c l e: ~ N=10 ; ~ W T-6 B I O: ~ N=12 ; ~ S y n g a p ~} 1^{+/-6 B I O: ~ N=14, ~ F ~}(3,88)=1.481, p=0.2252$, G) WTVehicle: N=12; Syngap 1 ${ }^{+-}$-Vehicle: N=10; WT-6BIO: N=12; Syngap $1^{+-}-6 \mathrm{BIO}$ : N=14, F $(3,88)=0.6549, \mathrm{p}=0.5820$, E) P10-80 where behavior was done at P80, WT-Vehicle: N=9; Syngap1 ${ }^{+/}-$Vehicle: N=6; WT-6BIO: N=10;

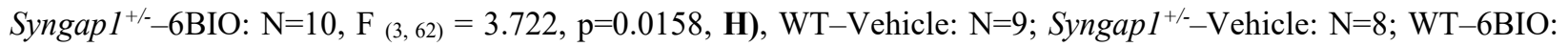
$\mathrm{N}=10$; Syngap ${ }^{+}=-6 \mathrm{BIO}: \mathrm{N}=10, \mathrm{~F}_{(3,66)}=2.692, \mathrm{p}=0.0532$, and $\left.\mathbf{F}\right) \mathrm{P} 30-80$ where behavior was done at $\mathrm{P} 80, \mathrm{~N}=12$; Syngap 1 $^{+/-}$-Vehicle: N=14; WT-6BIO: N=12; Syngap1 ${ }^{+/-}-6 \mathrm{BIO}: \mathrm{N}=18, \mathrm{~F}_{(3,104)}=2.909, \mathrm{p}=0.0381$, I), WT-Vehicle: N=12; Syngap 1 ${ }^{+/-}$-Vehicle: N=13; WT-6BIO: N=12; Syngap 1 ${ }^{+/-6 B I O: ~ N=18, ~ F ~}{ }_{(3,102)}=2.616, p=0.0551$. Two-way ANOVA, Tukey's multiple comparisons test.

Figure 5: 6BIO hyperpolarises GABA reversal potential at P15-16 in Syngap $^{+/-}$mice and corrects LTP in the post-critical period of development:

A) Mice were injected 6BIO from P30-80; thereafter, fluoroethyl-based seizure threshold was evaluated and plotted as grouped data showing individual points for tonic-clonic seizure. $6 \mathrm{BIO}$ increased the threshold for tonic-clonic, similar to WT levels, in Syngap 1 ${ }^{+/} . \mathrm{F}_{(1,25)}=3.354, \mathrm{p}=0.0790$, WT-Vehicle: N=9; Syngap 1 ${ }^{+/-}$-Vehicle: N=7; WT-6BIO: $\mathrm{N}=7$; Syngap 1 ${ }^{+/}-6 \mathrm{BIO}$ : N=6. B) Grouped data for $\mathrm{E}_{\mathrm{GABA}}$ estimated from I-V curve from individual WT (Vehicle and 
$6 \mathrm{BIO}$ treated) and Syngap1 ${ }^{+/}$mice (Vehicle and 6BIO treated). WT-Vehicle: N=5, n=5; Syngap ${ }^{+/}-$-Vehicle: N=4, $771 \mathrm{n}=6$; WT-6BIO: $\mathrm{N}=3, \mathrm{n}=5$; Syngap1 ${ }^{+/}-6 \mathrm{BIO}: \mathrm{N}=3, \mathrm{n}=7 ; \mathrm{F}_{(1,19)}=9.761, \mathrm{p}=0.0056$. C) For Group II, where injections 772 were done from P10-80, WT-Vehicle: N=4, n=8; Syngap $1^{+/}-$Vehicle: N=4, n=7; WT-6BIO: N=4, n=8; Syngap ${ }^{+/}$773 6BIO: $\mathrm{N}=4, \mathrm{n}=6, \mathrm{~F}_{(1,25)}=2.047, \mathrm{p}=0.1649$ and D) Group III, where injections were done from P30-80, WT-Vehicle: $774 \mathrm{~N}=3, \mathrm{n}=6$; Syngap 1 ${ }^{+/}$-Vehicle: $\mathrm{N}=4, \mathrm{n}=6$; WT-6BIO: N=5, n=9; Syngap 1 ${ }^{+/}-6 \mathrm{BIO}: \mathrm{N}=5, \mathrm{n}=9, \mathrm{~F}_{(1,26)}=4.731, \mathrm{p}=0.0389$, 775 slope of fEPSP was normalised to mean value of 15-minute baseline period and 45-minute post-LTP recordings were 776 performed. Example traces are average of those recorded in 1-2 min around the time point indicted (I and II). Two777 way ANOVA, Tukey's multiple comparisons test. 
Figure 1

(A)

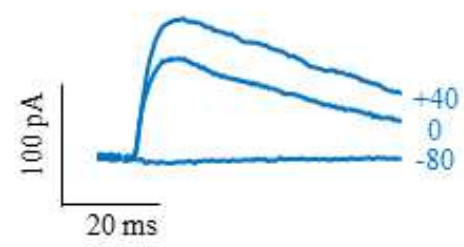

(B)
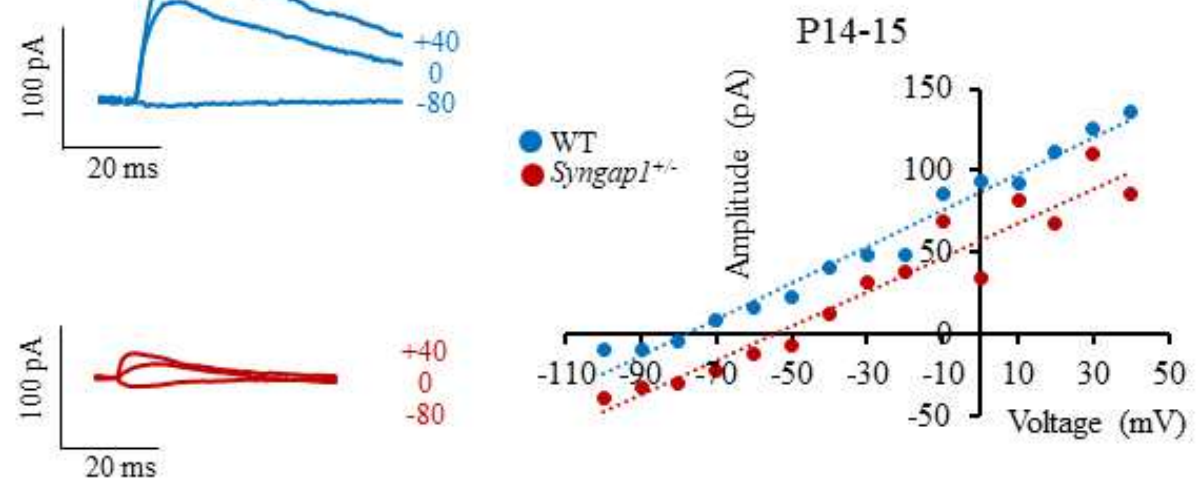

(C)

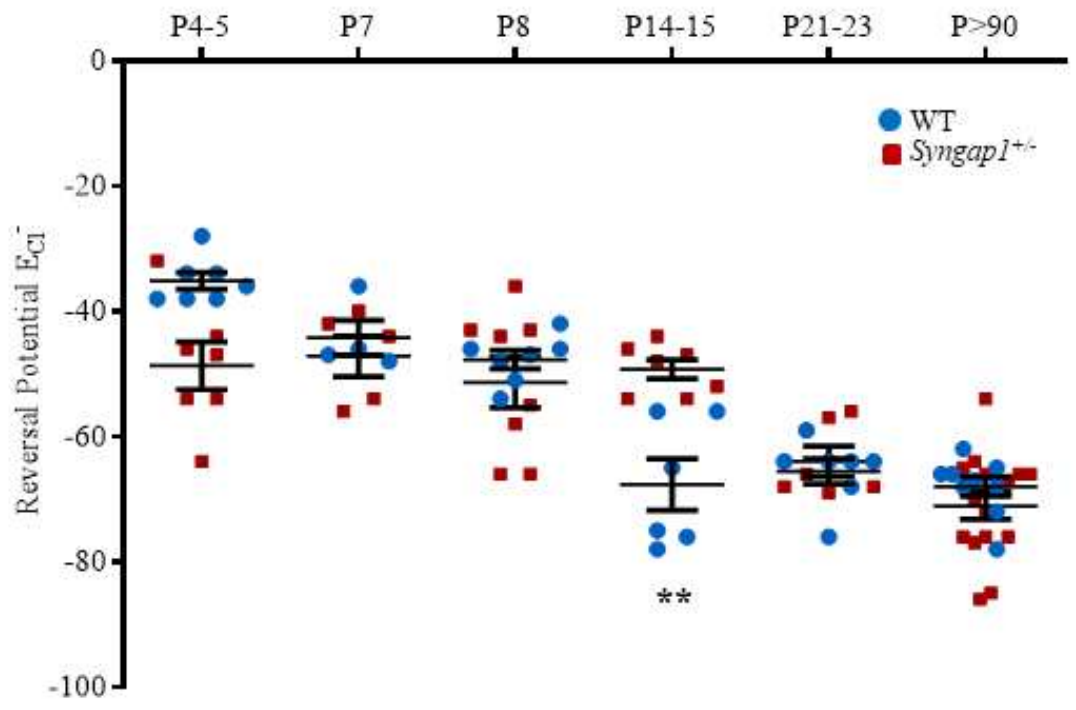

Figure 1

Neurons of Syngap1+/- mice show a shift in chloride reversal potential (ECI-) at P14-15: A) Left, Evoked representative $\mathrm{Cl}$ - mediated current traces at the indicated holding potentials of a Gramicidin-based perforated voltage-clamp experiment. Right, The graph to the right summarises the relationship of 
holding potential $(\mathrm{mV})$ to current amplitude for one representative experiment and depicts the trend as a linear fit curve. The experiments were conducted at P14-15 in WT mice. B) Same as A but in P14-15 Syngap $1+/-$. C) The graph summarises the reversal potentials of GABA receptor-mediated Clcurrent (ECl) in WT as well as Syngap1+/- at the indicated postnatal ages. P4-5: WT: $N=6, n=7,35 \pm 1.37$; Syngap1+/- : $N=4, n=7,48 \pm 3$, (NS: $p>0.05)$; P7: WT: $N=3, n=4,44 \pm 2.78$; Syngap1+/- $N=3, n=5,47 \pm 3$,(NS: $p>0.05)$; $P 8$ : WT $N=5, n=6,46 \pm 1$; Syngap1+/- : N=4, n=8, 51 \pm 4.04 , NS: $p>0.05$; P14-15: WT: $N=3, n=7$; Syngap1+/- :N=4, $n=6, * \star \star p<0.001 ; P 21-23$ WT, $N=4, n=6,65 \pm 2$; Syngap1+/- : N=3, $n=7,64 \pm 2, N S: p>0.05 ; P \geq 90: W T: N=7$, $n=15,68 \pm 1.53$; Syngap1+/- $N=5, n=9,71 \pm 2.18$, NS: $p>0.05$. $F(5,76)=6.83, p<0.0001$ for the interaction. Data are presented as single data points and means \pm SEM. N: number of mice, $n$ : number of cells. Two way ANOVA, Tukey's multiple comparisons test. 
Figure 2

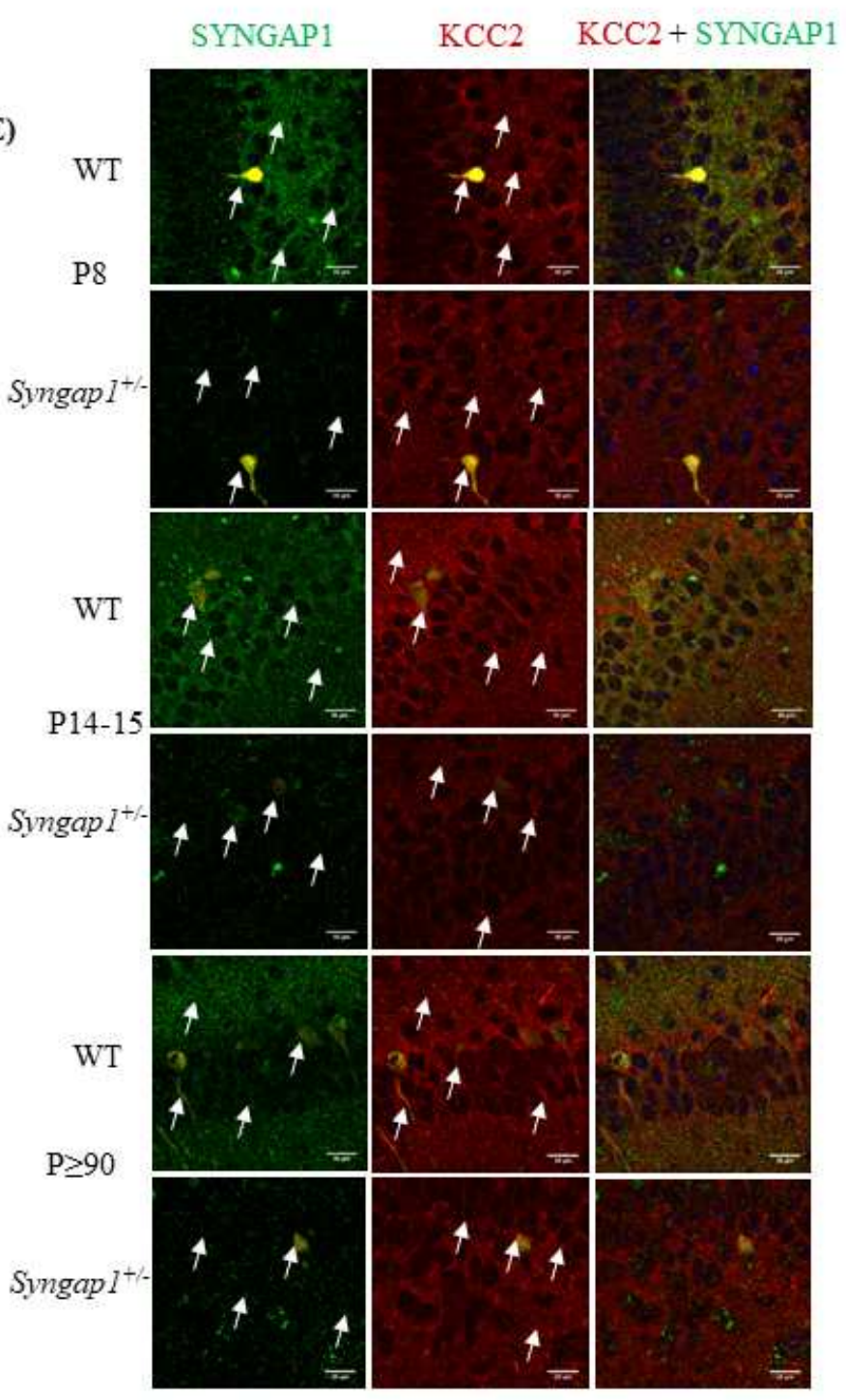

(A)

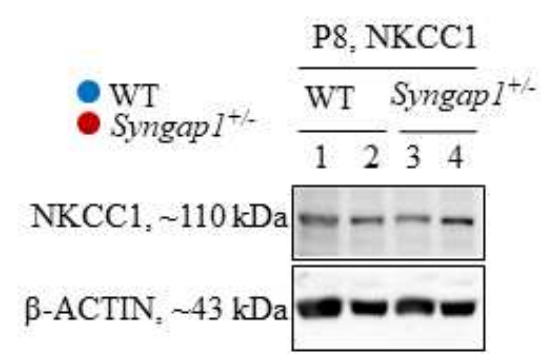

(B)

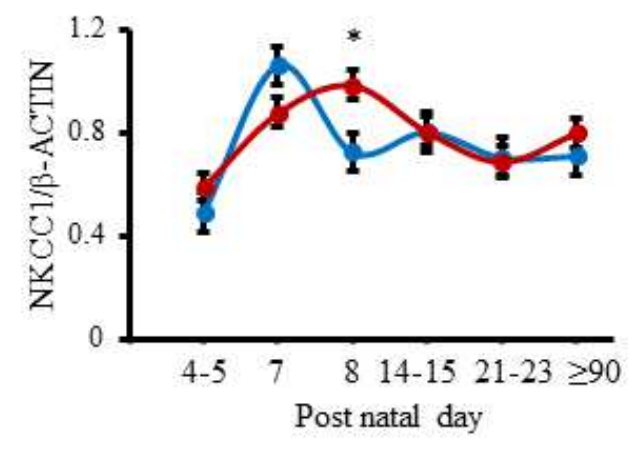

(C)

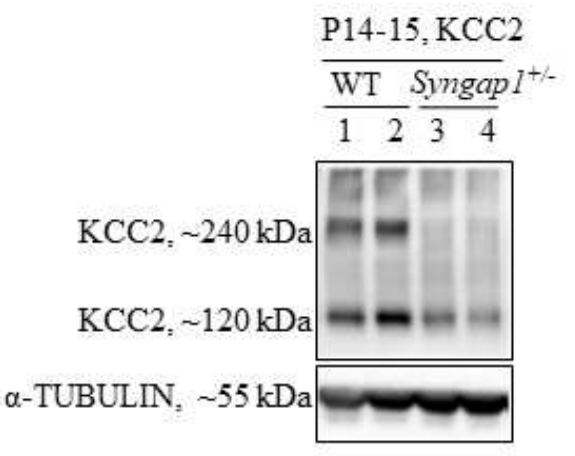

(D)

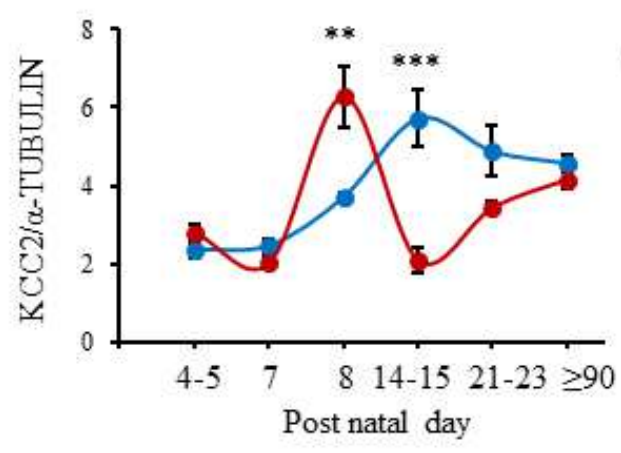

(E)

(F)

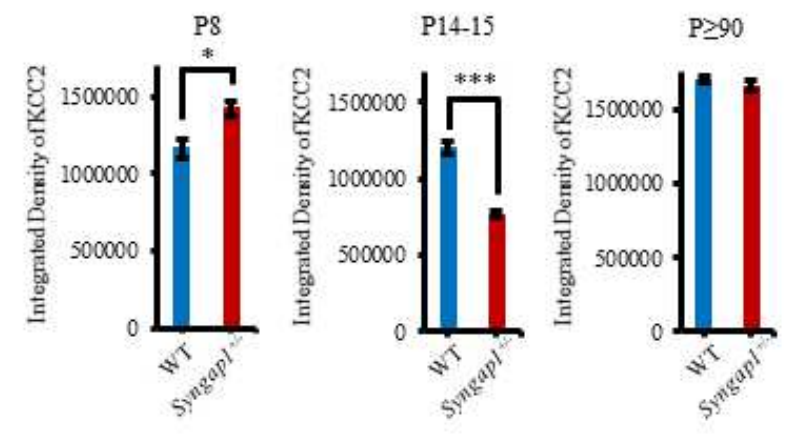

\section{Figure 2}

Age-dependent expression levels of NKCC1 and KCC2 Clco-transporters in WT and Syngap1+/- mice: A) Top, Representative NKCC1 immunoblots at P8 are depicted. B) Bottom, line graph summarizes NKCC1 expression levels at different post-natal ages for WT as well as Syngap1+/- . P4-5 (WT) N=7, 0.48 \pm 0.1 , (Syngap1+/-) N=11, $0.58 \pm 0.03$ (p: 0.1320); $P 7$ (WT) N=7, $1 \pm 0.1$, (Syngap1+/- 715 ) N=8, $0.87 \pm 0.1228$ ( $>>0.05) ; P 8$ (WT) N=6, 28 0.72 \pm 0.05 , (Syngap1+/-) N=6, 0.98 0.09 ( $\left.{ }^{*} p<0.05\right) ; P 14-15$ (WT) N=13, 
0.8 \pm 0.05 , (Syngap1+/-) N=10, 0.8 \pm 0.07 (p>0.05); P21-23 (WT) N=7, 0.7 \pm 0.03 , (Syngap1+/- ) N=7, $0.68 \pm 0.06$ ( $p>0.05) ; \geq P 90$ (WT) $N=10,0.7 \pm 0.07$, (Syngap1+/-) $N=10,0.79 \pm 0.08(p>0.05) . F(5,90)=1.48$, $p=0.2027$ for the interaction. C) Top, Representative P14-15 immunoblots for KCC2 are shown. D) Bottom, line graph summarizes KCC2 expression level during development in WT as well as Syngap1+/-. (P4-5 (WT) $N=9,2.3 \pm 0.18$, (Syngap1+/-) $N=9,2.8 \pm 0.18$ (p>0.05); $P 7$ (WT) $N=8,2.4 \pm 0.17$, (Syngap1+/) $N=8$, $2 \pm 0.17$ (p>0.05); P8 (WT) N=5, 3.7 \pm 0.12 , (Syngap1+/- ) N=6, 6.2 \pm 0.79 (**p<0.01); P14-15 (WT) N=7,

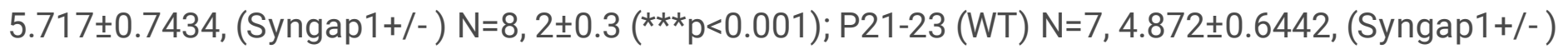
$N=7,3.4 \pm 0.1(p>0.05) ; \geq P 90$ (WT) $N=10,2.3 \pm 0.2$, (Syngap1+/- 723 ) $N=10,2.8 \pm 0.2(p>0.05) . F(5,82)=$ $14.46, p<0.0001$ for the interaction. Data are presented as mean \pm SEM. $N$ : number of mice. Two-way ANOVA, Tukey's multiple comparisons test. E) Representative immunofluorescence images depicting SYNGAP1 and KCC2 localisation and expression pattern in hippocampus region (DGGC for all age group and sections) in WT and Syngap1 +/- mice at P8, 14-15 and $\geq 90$. White arrows indicate punctate expression pattern of KCC2 and SYNGAP1. Blue colour represents the Hoescht staining of the nucleus, green coloured puncta are of SYNGAP1 protein, and KCC2 puncta surrounding soma and dendrites are presented in red. F) Bar graph representing the integrated density of WT and Syngap1+/- in the individual age group is shown in front of the respective panel of P8, 14-15 and $\geq 90$. P8 (WT) $n=4,1165283 \pm 64324$, (Syngap1+/- ) $n=5,1426211 \pm 47106$ ( $\left.{ }^{*}<<0.05\right)$; P14-15 (WT) $n=7,1202925 \pm 43917$, (Syngap1+/-) $n=6$, $766779 \pm 18128$ ( $\left.{ }^{* \star *} p<0.001\right) ; P \geq 90(W T) n=6,1697380 \pm 22155$, (Syngap1+/-) $n=8,1656486 \pm 32631$ $(p>0.05)$. Scale bar $=20 \mu \mathrm{m}$. Data are presented as mean \pm SEM. Unpaired t-test, $n$ : number of sections. 
Figure 3

(A)

Drug administration, Intraperitoneal (IP)

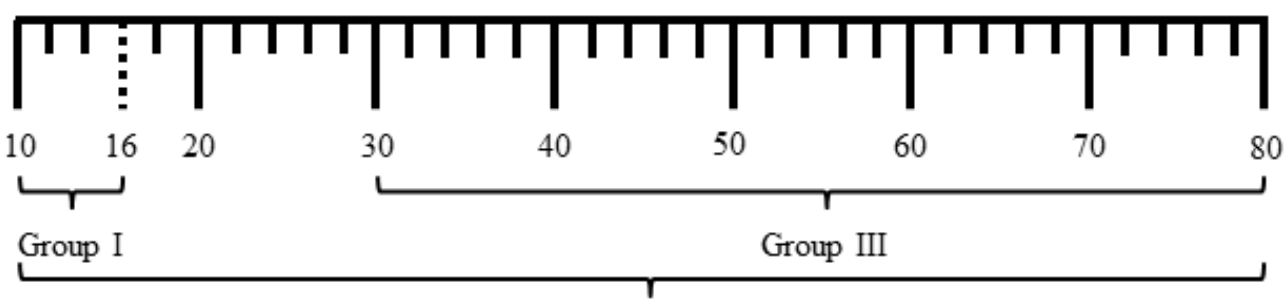

Group II

(B)

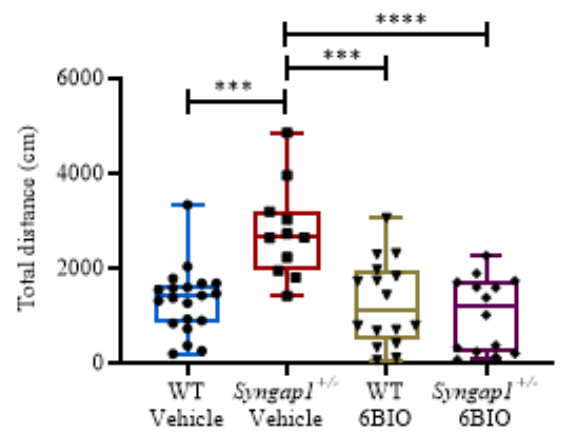

(E)

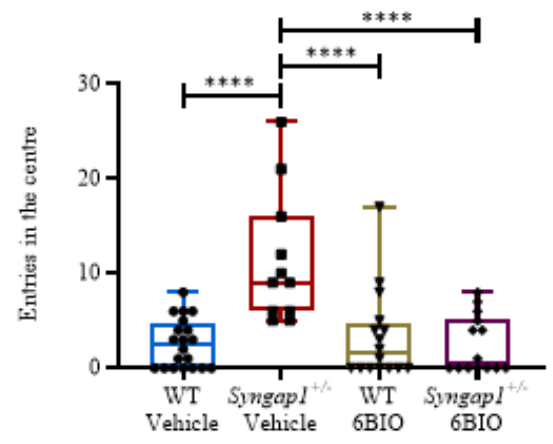

P10-80 at P16

$\mathrm{P} 10-80$ at P16
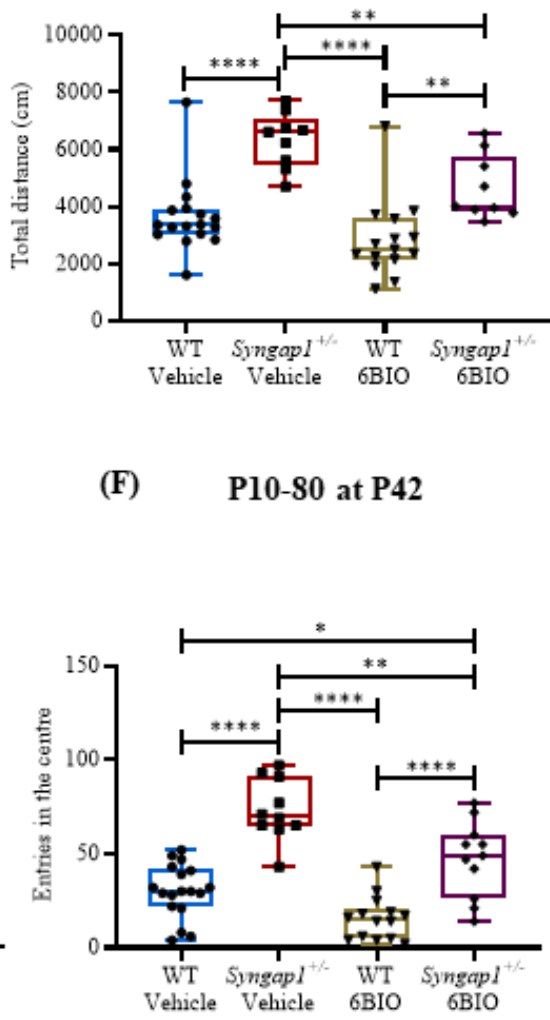

(F) $\quad \mathrm{P} 10-80$ at $\mathrm{P42}$
(D)

P30-80

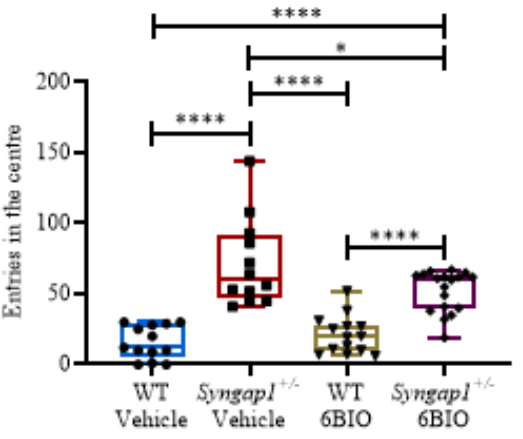

Figure 3

Figure 3: 6BIO corrects hyperactivity and anxiety deficits in Syngap1+/- A) Chart depicting the regime for $6 \mathrm{BIO}$ intraperitoneal injection ( $5 \mathrm{mg} / \mathrm{kg}$ ) and categorisation of age groups. B) Total distance travelled by the mice in open field chamber was grouped and shown as individual data points for $\mathrm{P} 10-80$ where behaviour was done at P16 WT-Vehicle: $\mathrm{N}=20$; Syngap1+/--Vehicle: $\mathrm{N}=11$; WT-6BIO: $\mathrm{N}=16$; Syngap1+/--6BIO: N=14, F(1, 57) = 14.83, p=0.0003, C) P10-80 where behaviour was done at P42, WT- 
Vehicle: N=17; Syngap1+/--Vehicle: N=9; WT-6BIO: N=15; Syngap1+/--6BIO: N=9, F $(1,44)=4.752$, $p=0.0347$, and D) P30-80, WT-Vehicle: N=14; Syngap1+/--Vehicle: N=14; WT-6BIO: N=16; Syngap1+/-6BIO: $N=16, F(1,56)=0.4686, p=0.4965$. E) Number of entries in the centre as a measure of anxiety was grouped and shown as individual data points for P10-80 where behaviour was done at P16, WT-Vehicle: $\mathrm{N}=20$; Syngap1+/--Vehicle: $\mathrm{N}=11$; WT-6BIO: $N=16$; Syngap1+/--6BIO: $N=14, F(1,57)=18.01, p<0.0001$, F) P10-80 where behaviour was done at P42, WT-Vehicle: N=18; Syngap1+/--Vehicle: N=10; WT-6BIO: $\mathrm{N}=15$; Syngap1+/--6BIO: $\mathrm{N}=11, \mathrm{~F}(1,50)=2.194, \mathrm{p}=0.1449$, and G) P30-80, WT-Vehicle: $\mathrm{N}=13$;

Syngap1+/--Vehicle: $N=12$; WT-6BIO: $N=15$; Syngap1+/--6BIO: $N=18, F(1,54)=6.002, p=0.0176$. Twoway ANOVA, Tukey's multiple comparisons test. 
Figure 4

Novel Object Recognition (NOR)

(A)

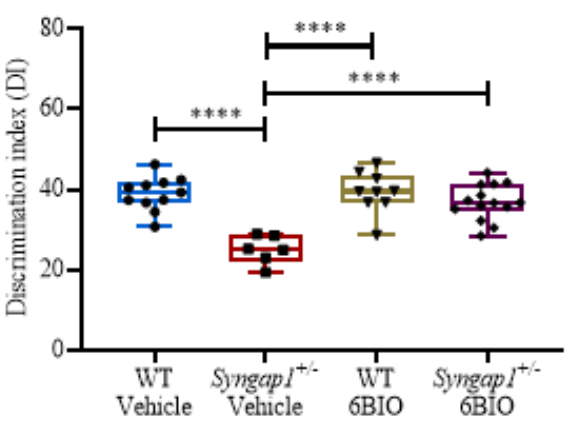

Social Interaction (SI)

P10-16 at P80

(B)

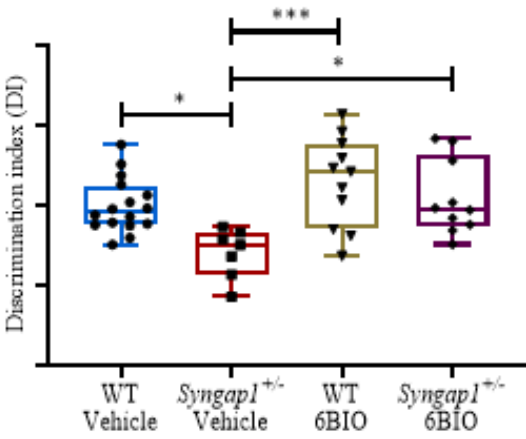

(C)

$\mathrm{P30-80}$ at P80

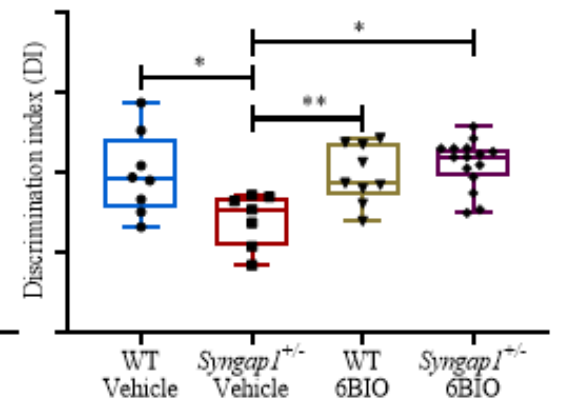

(D)

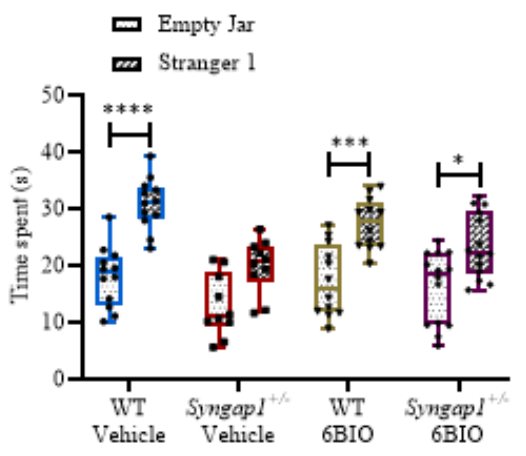

(E)

$\mathrm{P} 10-80$ at $\mathrm{PS0}$

(F)

P30-80 at P80
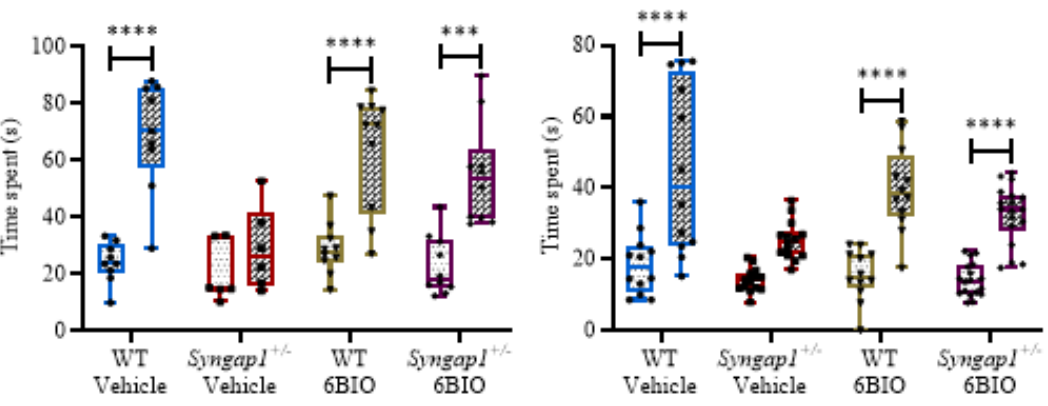

Social Preference (SP)

(G)

P10-16 at P80

(H)

P10-80 at P80

(I)

$\mathrm{P30-80}$ at P80
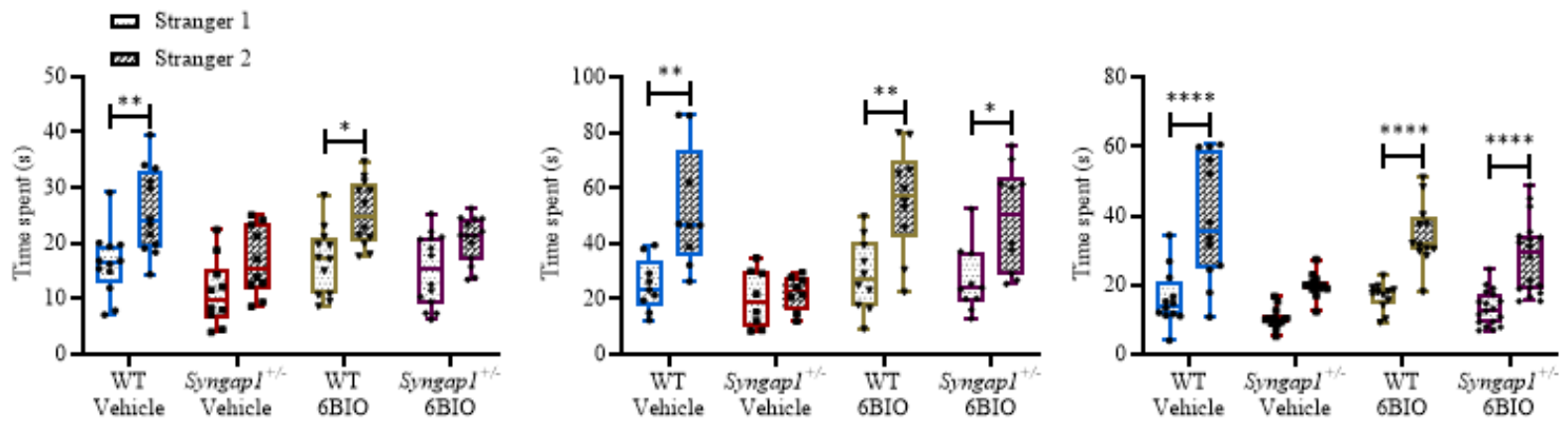

\section{Figure 4}

Figure 4: 6BIO corrects memory recognition and sociability deficits in Syngap1+/- particularly in the postcritical period of development: A) Discrimination index was plotted as the measure of recognition memory and plotted as individual data points for P10-16 where behavior was done at P80, WT-Vehicle: $\mathrm{N}=11$; Syngap1+/--Vehicle: N=6; WT-6BIO: N=9; Syngap1+/--6BIO: N=14, F (1, 36) = 14.76, p=0.0005, B) P10-80 where behavior was done at P80, WT-Vehicle: N=16; Syngap1+/--Vehicle: N=7; WT-6BIO: N=11;: 
$\mathrm{N}=10, \mathrm{~F}(1,40)=1.982, \mathrm{p}=0.1669$, and C) P30-80 where behavior was done at P80, WT-Vehicle: $\mathrm{N}=8$; Syngap1+/--Vehicle: $N=7$; WT-6BIO: $N=9$; Syngap1+/--6BIO: $N=15, F(1,35)=7.687, p=0.0089$. Social interaction and preference was evaluated as time spent with stranger 1 as compared to empty jar, and time spent with stanger 2 as compared to stranger 1 respectively for $D)$ P10-16 where behavior was done at P80, WT-Vehicle: $\mathrm{N}=12$; Syngap1+/--Vehicle: $N=10$; WT-6BIO: $N=12$; Syngap1+/--6BIO: N=14, F (3, 88) $=1.481, p=0.2252, G)$ WT-Vehicle: N=12; Syngap1+/--Vehicle: N=10; WT-6BIO: N=12; Syngap1+/-6BIO: $N=14, F(3,88)=0.6549, p=0.5820, E) P 10-80$ where behavior was done at $P 80, W T-V e h i c l e: ~ N=9$; Syngap1+/--Vehicle: $N=6$; WT-6BIO: $N=10$; Syngap1+/--6BIO: $N=10, F(3,62)=3.722, p=0.0158, H)$, WT-Vehicle: N=9; Syngap1+/--Vehicle: N=8; WT-6BIO: N=10; Syngap1+/--6BIO: N=10, F $(3,66)=2.692$, $\mathrm{p}=0.0532$, and F) P30-80 where behavior was done at P80, N=12; Syngap1+/--Vehicle: $N=14$; WT-6BIO: $\mathrm{N}=12$; Syngap1+/--6BIO: N=18, F (3, 104) = 2.909, $\mathrm{p}=0.0381$, I), WT-Vehicle: $\mathrm{N}=12$; Syngap1+/--Vehicle: $\mathrm{N}=13$; WT-6BIO: $\mathrm{N}=12$; Syngap1+/--6BIO: $\mathrm{N}=18, \mathrm{~F}(3,102)=2.616, \mathrm{p}=0.0551$. Two-way ANOVA, Tukey's multiple comparisons test. 
Figure 5

(A)

(B)

Seizure threshold; P30-80
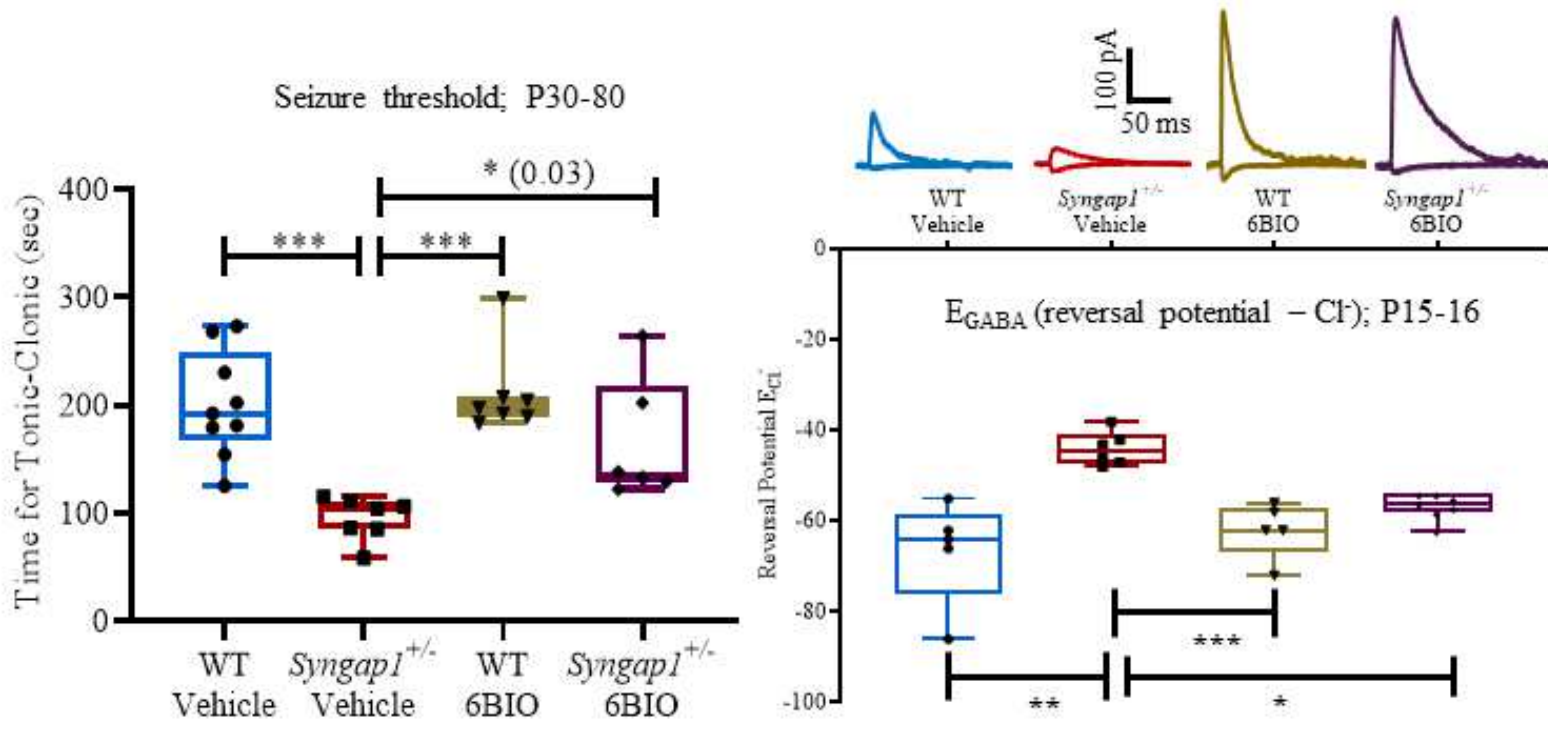

(C)

(D)
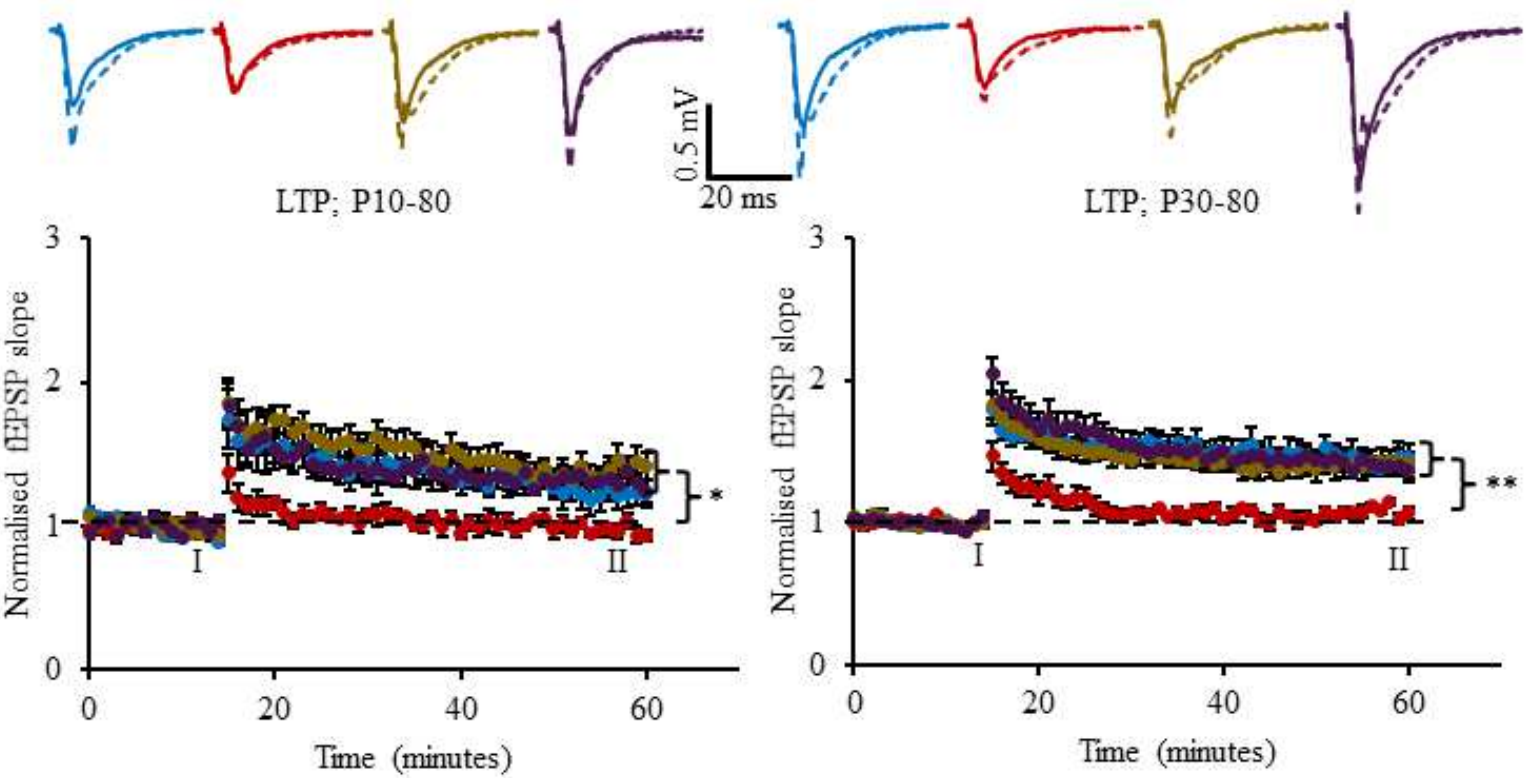

\section{Figure 5}

Figure 5: 6BIO hyperpolarises GABA reversal potential at P15-16 in Syngap1+/- mice and corrects LTP in the post-critical period of development: A) Mice were injected 6BIO from P30-80; thereafter, fluoroethylbased seizure threshold was evaluated and plotted as grouped data showing individual points for tonicclonic seizure. 6BIO increased the threshold for tonic-clonic, similar to WT levels, in Syngap1+/-. $F(1,25)=3.354, p=0.0790$, WT-Vehicle: N=9; Syngap1+/--Vehicle: N=7; WT-6BIO: N=7; Syngap1+/--6BIO: 
$\mathrm{N}=6$. B) Grouped data for EGABA estimated from I-V curve from individual WT (Vehicle and 6BIO treated) and Syngap1+/- mice (Vehicle and 6BIO treated). WT-Vehicle: N=5, n=5; Syngap1+/-Vehicle: N=4, $n=6$; WT-6BIO: N=3, $n=5$; Syngap1+/--6BIO: $N=3, n=7 ; F(1,19)=9.761, p=0.0056$. C) For Group II, where injections were done from P10-80, WT-Vehicle: $N=4, n=8$; Syngap1+/--Vehicle: $N=4, n=7$; WT-6BIO: $N=4, n=8$; Syngap1+/-6BIO: $N=4, n=6, F(1,25)=2.047, p=0.1649$ and $D)$ Group III, where injections were done from P30-80, WT-Vehicle: $N=3, n=6$; Syngap1+/--Vehicle: $N=4, n=6$; WT-6BIO: $N=5, n=9$; Syngap1+/-6BIO: $N=5$, $n=9, F(1,26)=4.731, p=0.0389$, slope of fEPSP was normalised to mean value of 15 -minute baseline period and 45-minute post-LTP recordings were performed. Example traces are average of those recorded in 1-2 min around the time point indicted (I and II). Two-way ANOVA, Tukey's multiple comparisons test.

\section{Supplementary Files}

This is a list of supplementary files associated with this preprint. Click to download.

- SI6biocorrectspathophysiologyVermaClementetal.pdf 